\title{
TU/e emonownen

\section{Investigating the effect of different impurities on plasma detachment in linear plasma machine Magnum-PSI}

\section{Citation for published version (APA):}

Perillo, R., Chandra, R., Akkermans, G. R. A., Classen, I. G. J., \& Korving, S. Q. (2019). Investigating the effect of different impurities on plasma detachment in linear plasma machine Magnum-PSI. Physics of Plasmas, 26(10), [102502]. https://doi.org/10.1063/1.5120180

DOI:

$10.1063 / 1.5120180$

Document status and date:

Published: 01/10/2019

\section{Document Version:}

Publisher's PDF, also known as Version of Record (includes final page, issue and volume numbers)

\section{Please check the document version of this publication:}

- A submitted manuscript is the version of the article upon submission and before peer-review. There can be important differences between the submitted version and the official published version of record. People interested in the research are advised to contact the author for the final version of the publication, or visit the $\mathrm{DOI}$ to the publisher's website.

- The final author version and the galley proof are versions of the publication after peer review.

- The final published version features the final layout of the paper including the volume, issue and page numbers.

Link to publication

\section{General rights}

Copyright and moral rights for the publications made accessible in the public portal are retained by the authors and/or other copyright owners and it is a condition of accessing publications that users recognise and abide by the legal requirements associated with these rights.

- Users may download and print one copy of any publication from the public portal for the purpose of private study or research.

- You may not further distribute the material or use it for any profit-making activity or commercial gain

- You may freely distribute the URL identifying the publication in the public portal.

If the publication is distributed under the terms of Article 25fa of the Dutch Copyright Act, indicated by the "Taverne" license above, please follow below link for the End User Agreement:

www.tue.nl/taverne

Take down policy

If you believe that this document breaches copyright please contact us at:

openaccess@tue.nl

providing details and we will investigate your claim. 


\section{Investigating the effect of different impurities on plasma detachment in linear plasma machine Magnum-PSI}

Cite as: Phys. Plasmas 26, 102502 (2019); https://doi.org/10.1063/1.5120180

Submitted: 17 July 2019 . Accepted: 11 September 2019 . Published Online: 01 October 2019

R. Perillo (D), R. Chandra, G. R. A. Akkermans, I. G. J. Classen, S. Q. Korving, and Magnum-PSI Team

\section{ARTICLES YOU MAY BE INTERESTED IN}

Magnetic mirror end-plugged by field-reversed configurations formed via rotating magnetic fields

Physics of Plasmas 26, 102501 (2019); https://doi.org/10.1063/1.5116173

Performance of Wendelstein 7-X stellarator plasmas during the first divertor operation phase Physics of Plasmas 26, 082504 (2019); https://doi.org/10.1063/1.5098761

Quantum hydrodynamics for plasmas-Quo vadis?

Physics of Plasmas 26, 090601 (2019); https://doi.org/10.1063/1.5097885

\begin{tabular}{|l|l|l|}
\hline AVS Quantum Science & $\begin{array}{l}\text { A high impact interdisciplinary } \\
\text { journal for ALL quantum science }\end{array}$ \\
AIP ACCEPING SUBMISSIONS \\
\hline Autshing
\end{tabular}




\title{
Investigating the effect of different impurities on plasma detachment in linear plasma machine Magnum-PSI
}

Cite as: Phys. Plasmas 26, 102502 (2019); doi: 10.1063/1.5120180

Submitted: 17 July 2019 - Accepted: 11 September 2019 .

Published Online: 1 October 2019

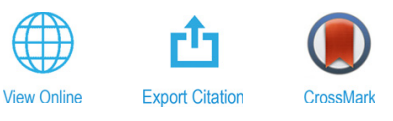

R. Perillo, (D) R. Chandra, G. R. A. Akkermans, I. G. J. Classen, S. Q. Korving, and Magnum-PSI Team

\section{AFFILIATIONS}

DIFFER-Dutch Institute for Fundamental Energy Research, De Zaale 20, 5612AJ Eindhoven, The Netherlands

\begin{abstract}
To achieve a tolerable heat and particle flux to the divertor target of fusion reactors, the so-called plasma detachment is essential to be set up and controlled. Impurity seeding facilitates the achievement of such a regime, mostly due to the enhanced plasma radiation led by the excitation-relaxation cycle of such species. Little is known about the impurity-induced plasma chemical processes occurring in the divertor region during detachment operation. In this work, the influence of three different impurities, i.e., $\mathrm{N}_{2}$, Ar, and He, on detachment performance is studied. To do so, experimental campaigns on the linear plasma machine Magnum-PSI have been carried out. Results highlight the beneficial role of $\mathrm{N}_{2}+\mathrm{H}_{2}$ seeding, decreasing the plasma pressure in front of the target, leading to a reduced heat load compared to the pure $\mathrm{H}_{2}$ seeding case. An opposite trend has been found concerning He and Ar puffing. In fact, injection of $\mathrm{H}_{2}+\mathrm{He}$ and $\mathrm{H}_{2}+\mathrm{Ar}$ gas mixtures led to an increased heat flux. To address the importance of different plasma-chemical reaction paths, global plasma models have been used. The resulting reduced reaction schemes for $\mathrm{Ar}+\mathrm{H}_{2}, \mathrm{He}+\mathrm{H}_{2}$, and $\mathrm{N}_{2}+\mathrm{H}_{2}$ have been implemented in B2.5-Eunomia, a coupled code consisting of a Monte Carlo code treating the transport of neutrals and a fluid code solving plasma equations. Simulation results qualitatively reproduce the favorable effect of $\mathrm{N}_{2}$, while confirming the deteriorating effect of $\mathrm{He}$ and Ar on a detachedlike hydrogen plasma. We point the synergetic role of $\mathrm{H}_{2}+\mathrm{N}_{2}$ to be due to molecular-driven ion recombination, i.e., $\mathrm{N}$-molecular-assisted recombination (MAR). A direct comparison of the collision frequency between N-MAR and MAR is showed, highlighting the crucial importance of the former in reducing the ion and heat flux to the target plate.
\end{abstract}

Published under license by AIP Publishing. https://doi.org/10.1063/1.5120180

\section{INTRODUCTION}

Understanding how to limit and control the enormous heat and particle flux foreseen to be deposited on the divertor plates of future nuclear fusion reactors, e.g., ITER, is one of the most crucial issues to be solved in order to achieve fusion electricity. ${ }^{1}$ The plasma ejected from the core is channeled along the Scrape-Off-Layer (SOL) toward the plasma-facing-components (PFC) ${ }^{2}$ located in the divertor region. ${ }^{3}$ Divertor plasma parameters in ITER are expected to be $\mathrm{n}_{\mathrm{e}}>10^{20} \mathrm{~m}^{-3}$ with $\mathrm{T}_{\mathrm{e}}<5 \mathrm{eV}$, leading to head loads of about $10 \mathrm{MW} \mathrm{m}^{-2}$ for steady state operation and up to a few gigawatts per meter square during intrinsic instabilities of the core such as edge-localized-modes (ELMs). ${ }^{4}$ Power is conveyed to the PFC via the ion potential energy, kinetic energy of electrons, ions, and neutrals, and via radiated power. ${ }^{5}$ To make such heat flux tolerable, the so-called detached plasma regime has to be achieved. ${ }^{6}$ Detachment is characterized by a plasma pressure reduction along magnetic field lines in the direction of the divertor target; such a drop is due to momentum transfer by means of electron/ion elastic collisions with neutrals and charge exchange, plasma radiation, and volume recombination. The heat flux to the target, $q_{w}$, can be expressed as

$$
q_{w}=\Gamma\left(\gamma \mathrm{k}_{\mathrm{b}} T_{e}+E_{i}\right)[\mathrm{Wm}-2 \mathrm{~s}-1]
$$

where $\Gamma$ is the particle flux, $\gamma$ is the sheath heat transmission coefficient, $\mathrm{T}_{\mathrm{e}}$ is the electron temperature, and $\mathrm{E}_{\mathrm{i}}$ is the ion potential. ${ }^{7}$ The sole plasma cooling is not enough to minimize the power load to tolerable values; hence, reducing the particle flux to the target is necessary. In hydrogen plasma scenarios, this occurs by means of electron-ion recombination processes (EIR) and molecular-assisted recombination (MAR), both producing electronically excited states whose energy will be released in the form of photons. These processes are

$$
\begin{gathered}
H^{+}+e^{-}+e^{-} \rightarrow H^{*}(n \geq 6)+e^{-}, \quad \text { EIR, } \\
H^{+}+H_{2}(v) \rightarrow H_{2}^{+}+H, \quad \operatorname{MAR}(\operatorname{step} 1), \\
H_{2}^{+}+e^{-} \rightarrow H+H^{*}(n=2-4), \quad \operatorname{MAR}(\operatorname{step} 2) .
\end{gathered}
$$

In such a way, ions are converted to neutrals before reaching the target, thus avoiding the release of the potential and kinetic energy onto 
the plate ${ }^{8}$ and preventing erosion of PFC. In divertor plasma detachment, volumetric processes play a key role in extinguishing charged particles, eventually reducing the heat flux. ${ }^{9,10}$ In this paper, the importance of hydrogenic volume recombination is compared to impurity-driven recombination processes. In particular, light is shed on the mechanisms leading to the neutralization of hydrogen plasma induced by impurity-driven reactions (Sec. IV).

Experiments in tokamaks since the mid-1990s have demonstrated steady-state detached regimes by puffing neutral gas in the divertor region, ${ }^{11}$ observing the recombination front moving upward from the PFC. ${ }^{12}$ Furthermore, seeding of the so-called impurities in the tokamak mid-plane and/or in the divertor region facilitates the achievement of detachment. ${ }^{13}$ Nitrogen is currently the leading candidate for impurity seeding in ITER, ${ }^{14}$ given its radiative capabilities. Other species, such as argon and helium, have been studied as potential impurities for detachment and plasma cooling purposes. ${ }^{15}$ Little is known about the effect on recombination mechanisms and plasma parameters that these species may cause once injected into such highdensity low-temperature divertor-relevant hydrogen plasma.

Linear machines, sometimes referred to as divertor simulators, have actively contributed to a deeper understanding of detachment and plasma-edge physics. The great diagnostics accessibility, together with the capability of sustaining a long steady-state pulse and the relatively low cost of operation, ${ }^{16}$ makes linear machines a fruitful tool to study plasma-neutrals interactions occurring during impurity seeding in detail.

In this work, we investigate the influence of three different impurities, $\mathrm{N}_{2}, \mathrm{He}$, and Ar, together with $\mathrm{H}_{2}$, in the target chamber of the recently upgraded linear machine Magnum-PSI. A description of the apparatus and the diagnostics that have been used is presented in Sec. II. To underline the most relevant plasma chemistry in such scenarios, global plasma models have been set up and will be presented in Sec. V. The most relevant plasma processes highlighted with global modeling have been implemented in a spatially resolved coupled code, i.e., Eunomia, a 3D Monte Carlo code simulating the transport of neutrals in linear machines and B2.5, a spatially resolved multifluid code that solves plasma equations. The aim is to study the behavior of different species and their influence on plasma detachment with both experimental observations and dedicated numerical simulations. The modeling pursued in this work with B2.5-Eunomia has to be considered as a "code experiment," rather than a quantitative benchmarking with experimental data. The scope is to highlight new relevant volumetric mechanisms occurring in a detachedlike hydrogen plasma. In fact, the inclusion of the plasma chemistry induced by the presence of impurities in-state-of-the-art codes is a necessary step toward a full description and understanding of the physics governing divertor plasmas during detachment operation. Although beyond the scope of this work, to carry out quantitative comparisons, dedicated studies on the free-parameters, i.e., cross field transport coefficients, potential boundaries, and plasma flow from the source might be needed. Moreover, the implementation of a certain class of reactions including $\mathrm{N}_{2}(\mathrm{v})$ as a reactant would improve the accuracy of the overall analysis [to the knowledge of the authors, no scaling laws regarding the interaction between $\mathrm{N}_{2}(\mathrm{v})$ and hydrogen plasma species have ever been published].

\section{EXPERIMENTAL SETUP AND DIAGNOSTICS}

Magnum-PSI is a linear plasma generator built to mimic the plasma-surface-interactions (PSI) that will occur in the ITER divertor. The machine can achieve plasma parameters of $\mathrm{T}_{\mathrm{e}} \leq 5 \mathrm{eV}$ and $\mathrm{n}_{\mathrm{e}}$ $\geq 10^{19} \mathrm{~m}^{-3}$ with ion flux up to $10^{25} \mathrm{~m}^{-2} \mathrm{~s}^{-1}$. Those conditions lead to heat loads to the target of $\sim 10 \mathrm{MW} \mathrm{m}^{-2}$, i.e., the expected steadystate loads onto the ITER divertor plates. ${ }^{18}$ By using a pulsed source, ELM-like heat loads up to few gigawatt per meter square can also be achieved. ${ }^{19}$ In this work, only steady-state scenarios have been studied, both experimentally and by modeling. Magnum-PSI is characterized by three differentially pumped chambers, i.e., source and middle and target chamber, as can be seen in Fig. 1.

The plasma is generated by a cascaded arc source ${ }^{20}$ and is confined by applying a magnetic field generated by a superconducting magnet. The beam travels through the three chambers and eventually reaches the target plate. Differential pumping between all three chambers is applied in order to minimize the presence of neutrals along the beam path, which would cause a cooling of the plasma and higher recombination, resulting in lower electron density. The target used in the experiments presented in this work consists of a tungsten circular target with a diameter of $3 \mathrm{~cm}$ and a thickness of $1 \mathrm{~mm}$. A more detailed description of the machine can be found in Ref. 21 .

Plasma parameters (temperature and density) have been diagnosed using a Thomson Scattering (TS) system ${ }^{22}$ measuring at $3 \mathrm{~cm}$ in front of the target. A hydrogen plasma beam has been adopted for all the scenarios examined in this paper.

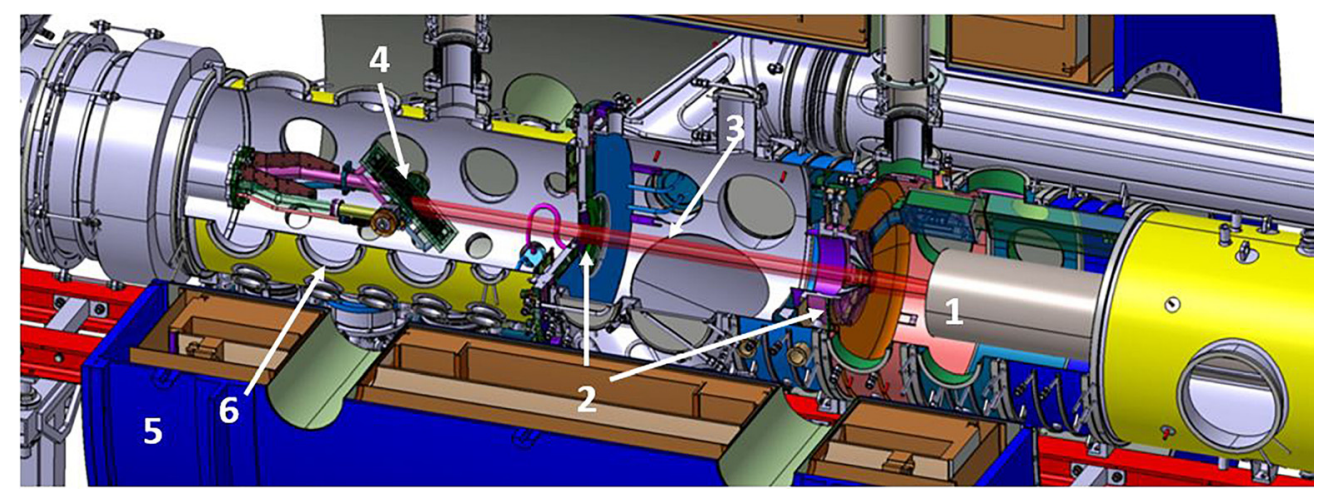

FIG. 1. Design of linear plasma machine Magnum-PSI. The numbers correspond to: 1, Plasma source, 2, Skimmers separating the three chambers, 3, Plasma beam, 4 , Target, 5, Superconducting magnet, and 6, Impurity gas introduction location. 


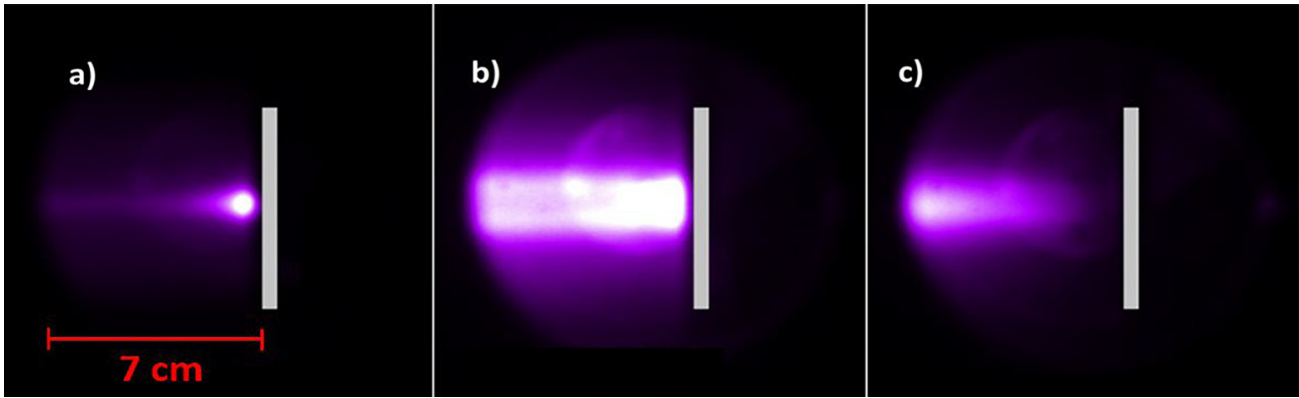

FIG. 2. Background neutral pressure scan on a hydrogen plasma beam facing the target. (a) Pressure $=0.3 \mathrm{~Pa} ;(\mathrm{b})=4.4 \mathrm{~Pa} ;(\mathrm{c})=16.8 \mathrm{~Pa}$. The gray part represents the target location.

To study plasma radiation during $\mathrm{H}_{2}$ and $\mathrm{N}_{2}$ seeding in detachment experiments, a resistive bolometer has been used. More details on this diagnostic can be found in Ref. 23. The gas seeding valve, necessary for plasma detachment studies, is located laterally in the target chamber just behind the target. To measure the background neutral pressure in the chamber, a baratron type MKS 627B is used. It is located further behind the target compared to the seeding valve.

A two-channel fiber optic spectrometer (AvaSpec-ULS2048) has been used during nitrogen seeding experiments to observe the line intensity at $336 \mathrm{~nm}$. Such wavelength corresponds to the $\mathrm{NH}^{*}\left(\mathrm{~A}^{3} \Pi->\mathrm{X}^{3} \Sigma^{-}\right)$electronic transition. That species is of great interest in our work, concerning both experiments and simulations. The OES (Optical Emission Spectroscopy) view is located at the same axial coordinates as TS, i.e., $3 \mathrm{~cm}$ in front of the target. To study the heat and particle flux deposited to the tungsten target, calorimetry has been used.

\section{PLASMA DETACHMENT WITH HYDROGEN SEEDING}

Plasma detachment has been successfully achieved in MagnumPSI by increasing the background neutral pressure in the target chamber by actively seeding hydrogen gas. In Fig. 2, three snapshots taken during a background pressure scan are shown. Hydrogen plasma has been used. Images are taken with a phantom camera V12.1. A balmer- $\alpha$ filter has been applied. The target is a tungsten disk with $3 \mathrm{~cm}$ diameter and $1 \mathrm{~mm}$ thick

Figure 2(a) shows a typical high-recycling regime, where ions recombine on the target and are re-emitted as ground state molecules in vibrational excitation or atoms. Those particles will be soon excited via electron-impact in the vicinity of the surface, given the short meanfree-path. Plasma parameters in such conditions were $\mathrm{T}_{\mathrm{e}}=3.94 \mathrm{eV}$ and $\mathrm{n}_{\mathrm{e}}=1.11 \times 10^{20} \mathrm{~m}^{-3}$ and the background neutral pressure was $0.3 \mathrm{~Pa}$. A recombining plasma is observed in Fig. 2(b); in such a case, plasma parameters were $\mathrm{T}_{\mathrm{e}}=0.8 \mathrm{eV}$ and $\mathrm{n}_{\mathrm{e}}=2.4 \times 10^{20} \mathrm{~m}^{-3}$ with a pressure of 4.4 $\mathrm{Pa}$. In these conditions, recombination of ions occurs extensively $\left(\mathrm{T}_{\mathrm{e}}<2 \mathrm{eV}\right.$ and $\left.\mathrm{n}_{\mathrm{e}}>10^{20} \mathrm{~m}^{-3}\right)$. More specifically, MAR and threebody recombination, i.e., $\mathrm{H}^{+}+\mathrm{e}^{-}+\mathrm{e}^{-} \rightarrow \mathrm{H}^{*}(n>5)+\mathrm{e}^{-}$are the main processes leading to the observed emission throughout the beam ${ }^{24}$ together with the broadening of the emission. To unequivocally define the relative contribution of MAR and EIR on the scenario shown in Fig. 3(b), a dedicated CR (Collisional Radiative) model should be set up. This goes beyond the scope of this paper. Nevertheless, Balmer- $\alpha$ emission is mostly due to MAR processes, which are initiated by molecular hydrogen in the vibrational excited state. In fact, one can observe a hollowness in the emitted light from the plasma beam up to few $\mathrm{cm}$ in front of the target. Such an effect is due to $\mathrm{H}_{2(\mathrm{v}>4)}$ molecules coming
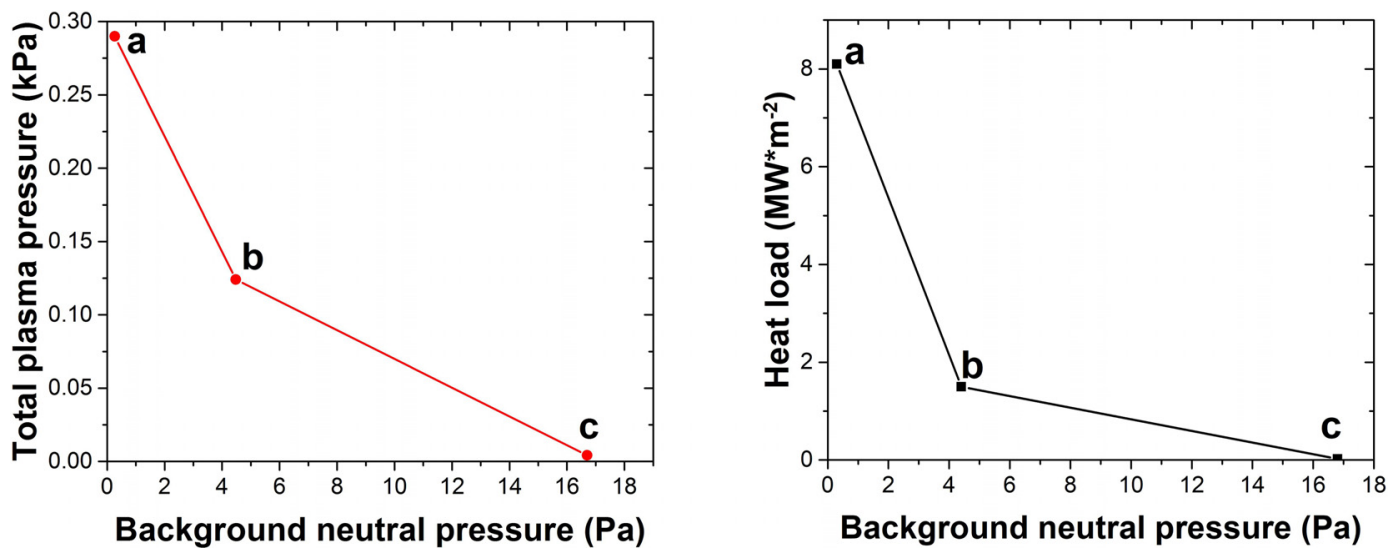

FIG. 3. (Left). Total plasma pressure as a function of background neutral pressure in the target chamber of Magnum-PSI. At a neutral pressure of $0.3 \mathrm{~Pa}$, plasma pressure is about $0.29 \mathrm{kPa}$ (point a). It goes down to $0.12 \mathrm{kPa}$ at $4.4 \mathrm{~Pa}$ (point b) and eventually falls to $0.0042 \mathrm{kPa}$ at $16.8 \mathrm{~Pa}$ (point c). (Right) Heat load to the target, calculated with Eq. (1), for the same background neutral pressures of Figs. 2 and 3 (left). 
from the side of the plasma beam that eventually undergo through MAR. The brightness in front of the target is due to $\mathrm{H}_{2(\mathrm{v}>4)}$ coming from the wall and undergoing the same process. The mean-free-path of those species is longer compared to Fig. 2(a) because of the milder conditions of the plasma $\left(\mathrm{T}_{\mathrm{e}}<1 \mathrm{eV}\right)$. Figure 2 (c) depicts an almost entirely extinguished plasma: neutral pressure was $16.8 \mathrm{~Pa}$ and led to parameters to be $\mathrm{T}_{\mathrm{e}}=0.16 \mathrm{eV}$ and $\mathrm{n}_{\mathrm{e}}=4 \times 10^{19} \mathrm{~m}^{-3}$. It is hereby proved that different degrees of detachment can be achieved by means of Magnum-PSI. To further characterize the above-mentioned three cases of study, total peaked static plasma pressure (dynamic ion pressure is not included) has been calculated assuming a quasineutral thermal plasma, i.e., $P_{p}=2 k T_{e} n_{e}$. Results are shown in Fig. 3.

Points (a), (b), and (c) in Fig. 3 (left and right) correspond to the same ones depicted in Fig. 2. The total plasma pressure, derived by Thomson scattering measurements, steeply decreases while enhancing the neutral background pressure by $\mathrm{H}_{2}$ gas puffing in the target chamber. It goes from $\mathrm{P}_{\text {plasma }} \approx 0.29 \mathrm{kPa}$ at $\mathrm{P}_{\text {neutrals }}=0.3 \mathrm{~Pa}$ (point a), to $\mathrm{P}_{\text {plasma }}=0.12 \mathrm{kPa}$ at $4.4 \mathrm{~Pa}$ (point $\mathrm{b}$ ) and eventually to $\mathrm{P}_{\text {plasma }}$ $=0.0042 \mathrm{kPa}$ at $\mathrm{P}_{\text {neutrals }}=16.8 \mathrm{~Pa}$ (point c). At the highest background neutral pressure, plasma is almost entirely recombined before reaching the watts target. Steady-state plasma detachment is achieved in Magnum-PSI by impurity seeding. Experiments regarding how different impurities injected together with $\mathrm{H}_{2}$ at different mixture ratios influence plasma detachment in ITER-divertor relevant conditions are presented and discussed in Sec. IV.

\section{PLASMA DETACHMENT WITH IMPURITY SEEDING ( $\mathrm{N}_{2}, \mathrm{Ar}, \mathrm{AND} \mathrm{He}$ )}

A comparative study among different impurity species and their effect on plasma detachment has been carried out. Impurities have been seeded, together with $\mathrm{H}_{2}$, with different mixing ratios defined by the partial pressure; the background neutral pressure in the target chamber has been kept constant at 2 and $4 \mathrm{~Pa}$, while changing the ratio as

$$
\frac{[\text { impurity }]}{\left[\mathrm{H}_{2}\right]+[\text { impurity }]} * 100=0 \%, 5 \%, 10 \%, 15 \%, 20 \% .
$$

Three different gas species have been puffed with hydrogen, i.e., nitrogen, helium, and argon. The last two species are poorly reactive, while
$\mathrm{N}_{2}$ and related compounds such as $\mathrm{NH}_{3}, \mathrm{NH}_{2}$, and $\mathrm{NH}$ react with species populating the generated hydrogen plasma, e.g., $\mathrm{H}^{+}, \mathrm{H}_{2}^{+}, \mathrm{H}$, and $\mathrm{H}_{2}(\mathrm{v}){ }^{25}$ In this section, we study experimentally the influence of different impurity seeding on plasma parameters by means of the plasma pressure and the heat flux collected at the target. The injected gas mixtures are $\mathrm{H}_{2}+\mathrm{N}_{2}, \mathrm{H}_{2}+\mathrm{He}$, and $\mathrm{H}_{2}+\mathrm{Ar}$, and the plasma pressure, calculated with Thomson scattering, is shown in Fig. 4. These measurements have been taken in the plasma volume, at $3 \mathrm{~cm}$ in front of the tungsten target.

For the scans of both background pressures, the baseline scenario, i.e., with only $\mathrm{H}_{2}$ puffing, corresponds to the first point, i.e., when no impurity was added into the mixture. Although each baseline scenario can be slightly different due to limited reproducibility of the machine, every scan is carried out maintaining the same experimental conditions among each other. At $2 \mathrm{~Pa}$ with $\mathrm{N}_{2}$ seeding up to $20 \%$, we observe a clear decay that leads to a plasma pressure loss of $\approx 25 \%$. In the helium case, a different trend is achieved. Here, the plasma pressure somewhat varies around $0.21 \mathrm{kPa}$ and remains almost constant. Regarding the Ar-seeding case, the behavior is similar to the helium one: after a small decrease at $5 \%, P_{\text {plasma }}$ increases by about $10 \%$ during the scans at $10 \%, 15 \%$, and $20 \%$ of impurity content, hence reducing the effectiveness of detachment. If on the one hand the addition of a mixture of $\mathrm{H}_{2} / \mathrm{N}_{2}$ is beneficial for plasma detachment compared to $\mathrm{H}_{2}$ puffing alone, the other two species show an opposite effect, enhancing the plasma pressure in front of the target.

To unequivocally investigate the effect of these impurities on plasma recombination, heat fluxes collected at the target have been diagnosed by means of calorimetry and results are reported in Fig. 5. The power deposited to the tungsten disk is calculated as $P(W)$ $=$ flow $\left(\frac{\mathrm{kg}}{\mathrm{s}}\right) d T(\mathrm{~K}) 4200\left(\frac{\mathrm{J}}{\mathrm{kg} \mathrm{K}}\right)$, with flow $=0.4 \frac{\mathrm{kg}}{\mathrm{s}}$ being the amount of cooling water passing through the diagnostic per second, $d T$ the water temperature difference before and after it has been passed through the heated component, and $4200 \mathrm{~J}$ is the energy needed to heat up 11 of water by $1 \mathrm{~K}$. It is worth stressing that for the calculation of the heat flux no direct measurements of plasma parameters are used; in such a way we can straightforwardly measure the actual heat transported by the plasma to the target. The power load at the target is mostly due to surface recombination of incoming hydrogen ions, where they release
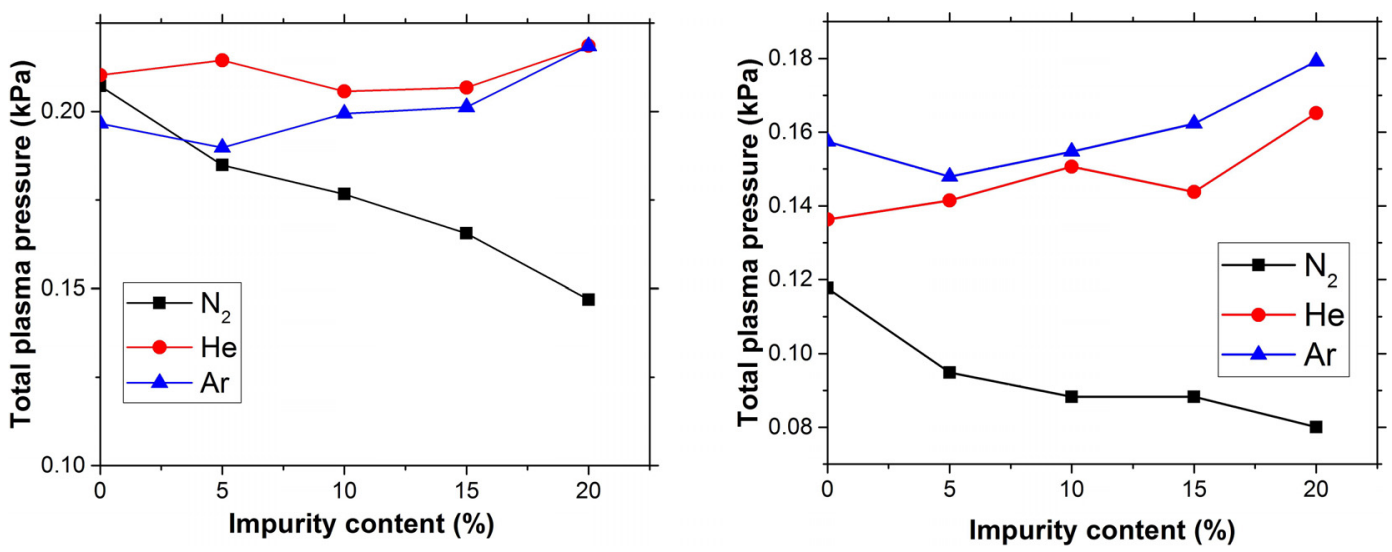

FIG. 4. Total plasma pressure as a function of impurity content for $\mathrm{N}_{2}$, He, and Ar. The neutral background pressure in the target vessel is constant at $2 \mathrm{~Pa}$ (left) and $4 \mathrm{~Pa}$ (right). 

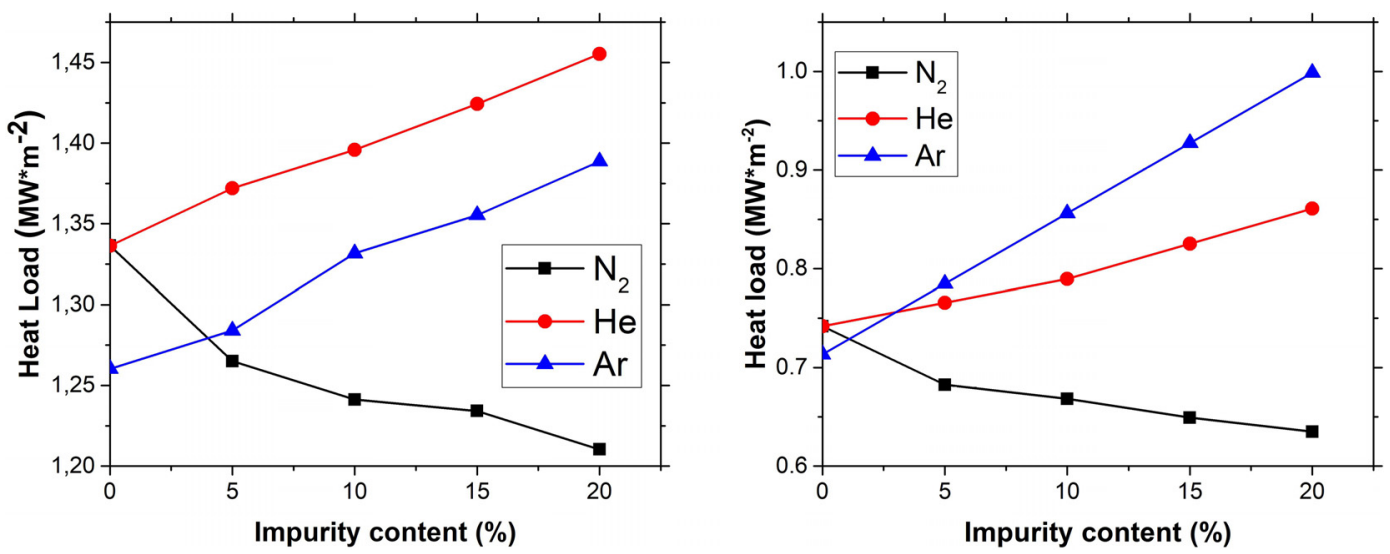

FIG. 5. Heat load on the $\mathrm{W}$ target for each impurity at different $\mathrm{H}_{2}$ /impurity mixing ratios at $2 \mathrm{~Pa}$ (left) and $4 \mathrm{~Pa}$ (right).

their potential and (part of their) kinetic energy, which causes heating of the material. In Fig. 5 (left), the starting value of heat load for the Ar seeding scan, i.e., $\mathrm{Ar}=0 \%$ is lower compared to $\mathrm{H}_{2} / \mathrm{N}_{2}$ and $\mathrm{H}_{2} / \mathrm{He}$ cases by $\approx 0.7 \mathrm{MW} \mathrm{m} \mathrm{m}^{-2}$. Although the experimental settings have been kept the same, plasma conditions were not perfectly reproducible. Nevertheless, for the scope of this work, the trend obtained by puffing different ratios of different species is the most relevant feature to be highlighted and studied.

At a background neutral pressure of $2 \mathrm{~Pa}$, when $\mathrm{H}_{2}$ is diluted with $\mathrm{He}$, the measured heat load increases by $\approx 11 \%$, from $0 \%$ to $20 \%$ of impurity content. Regarding $\mathrm{N}_{2}$, we obtain a net reduction of heat flux of about $12 \%$. Such findings further confirm the beneficial effect for detachment led by the presence of $\mathrm{N}_{2}$ in the seeded gas mixture. Argon puffing experiments are characterized by an enhancement of heat deposited to the surface of $\approx 12 \%$, implying a reduced detachment efficiency.

The same experiments have been carried out with a fixed background pressure of $4 \mathrm{~Pa}$ and results are plotted in Figs. 4 (right) and 5 (right). The same behavior is observed compared to the $2 \mathrm{~Pa}$ case; in fact, $P_{\text {plasma }}$ increases by $\approx 15 \%$ between $0 \%$ and $20 \%$ of impurity content, for both $\mathrm{He}$ and $\mathrm{Ar} . \mathrm{H}_{2} / \mathrm{N}_{2}$ puffing led to a plasma pressure reduction of $\approx 28 \%$. The heat flux is reduced by the presence of $\mathrm{N}_{2}$ by $18 \%$, while it is enhanced by $16 \%$ and almost $40 \%$ with $\mathrm{H}_{2} / \mathrm{He}$ and $\mathrm{H}_{2} /$ Ar, respectively.

According to these results, Ar seems to be the less beneficial species among the impurities exploited in this study. Helium shows a negative impact on plasma detachment as well, while nitrogen led to an improved detached state among both 2 and $4 \mathrm{~Pa}$ cases. Three different impurities have been tested in ITER-relevant hydrogen plasma at the same experimental conditions for the first time. The negative outcome on plasma pressure and heat flux of Ar and He seeding may be due to the dilution effect, i.e., fewer hydrogen molecules are inserted in the system; therefore, less molecule-driven ion recombination occurs in the volume phase. This is not the case for $\mathrm{N}_{2}$, which shows an effective improvement in the detached plasma performance. When mixtures of $\mathrm{H}_{2}+\mathrm{N}_{2}$ are injected into the vessel, the heat flux is subjected to a net decrease. This behavior is appointed by the authors to be due to the presence of $\mathrm{N}_{2}$-driven ion recombination processes, as discussed in Ref. 26. The role of $\mathrm{NH}_{\mathrm{x}}$ molecules, i.e., $\mathrm{NH}_{3}, \mathrm{NH}_{2}$, and $\mathrm{NH}$ as electron donors in the reaction with $\mathrm{H}^{+}$has been found to be of great importance in divertor-relevant hydrogen plasma. Specifically, the following two-step process was found by numerical simulations to be relevant:

(1) $\mathrm{H}^{+}+\mathrm{NH}_{x} \rightarrow \mathrm{H}+\mathrm{NH}_{x}^{+}$

(2) $\mathrm{NH}_{x}^{+}+\mathrm{e}^{-} \rightarrow \mathrm{NH}_{x-1}+\mathrm{H}$.

Such a mechanism is referred to as N-MAR, ${ }^{27}$ and is characterized by an ion conversion promptly followed by dissociative recombination. This process effectively converts ion to neutral, thus dissipating energy from the plasma via volumetric recombination. This may result in a reduced heat flux when increasing the $\mathrm{H}_{2}+\mathrm{N}_{2}$ puffing ratio. To investigate the presence of $\mathrm{N}_{2}-\mathrm{H}_{2}$ species in the plasma, optical-emissionspectroscopy has been adopted and the outcome is shown in Fig. 6.

On the left, the identification of the main peaks diagnosed with OES is shown. Balmer lines, in particular the transitions $n=5$ $\rightarrow n=2($ Balmer $\gamma)$ and $n=6 \rightarrow n=2($ Balmer $\delta)$ at $434 \mathrm{~nm}$ and $410 \mathrm{~nm}$ respectively, are shown. $\mathrm{N}_{2}$ transition $C^{3} \Pi->B^{3} \Pi$ at $338 \mathrm{~nm}$ is also present. Of particular interest is the peak at $336 \mathrm{~nm}$, which is due to the $\mathrm{NH}^{*}\left(\mathrm{~A}^{3} \Pi->\mathrm{X}^{3} \Sigma\right)$ transition, the $\mathrm{NH}$ radical being the electron donor in the N-MAR first step, i.e., ion conversion with $\mathrm{H}^{+}$in high density plasmas. On the right, the intensity of the $336 \mathrm{~nm}$ band is plotted as a function of $\mathrm{N}_{2}$ content in the puffed $\mathrm{H}_{2}+\mathrm{N}_{2}$ mixture and calculated as $\int \frac{I(\lambda)}{t(\text { exposure })} d \lambda$. The achieved trend clearly indicates a relevant presence of such species in the plasma, thus providing a further indication on the enhanced recombination of hydrogen ions led by $\mathrm{NH}_{\mathrm{x}}$ species. To study the radiated power emitted during the seeding scan, a bolometry system has been used. By such a diagnostic, we can include/exclude cooling phenomena led by relaxation of electronically excited species. Results are shown in Fig. 7.

The total radiated power, averaged over the 3 viewing channels, is calculated as

$$
P_{\text {rad }}=\frac{\pi^{2} l_{s, a p}^{2}}{A_{s} A_{a p}} d_{p} \Delta z P_{s},
$$

where $l_{s, a p}$ is the distance between the sensor and the aperture, $A_{s}$ is the sensor area, $A_{a p}$ is the aperture area, $d_{p}$ is the plasma diameter taken as the FWHM measured by Thomson scattering, $\Delta z$ is the axial width, and $P_{s}$ is the power received by the sensor of a bolometer 

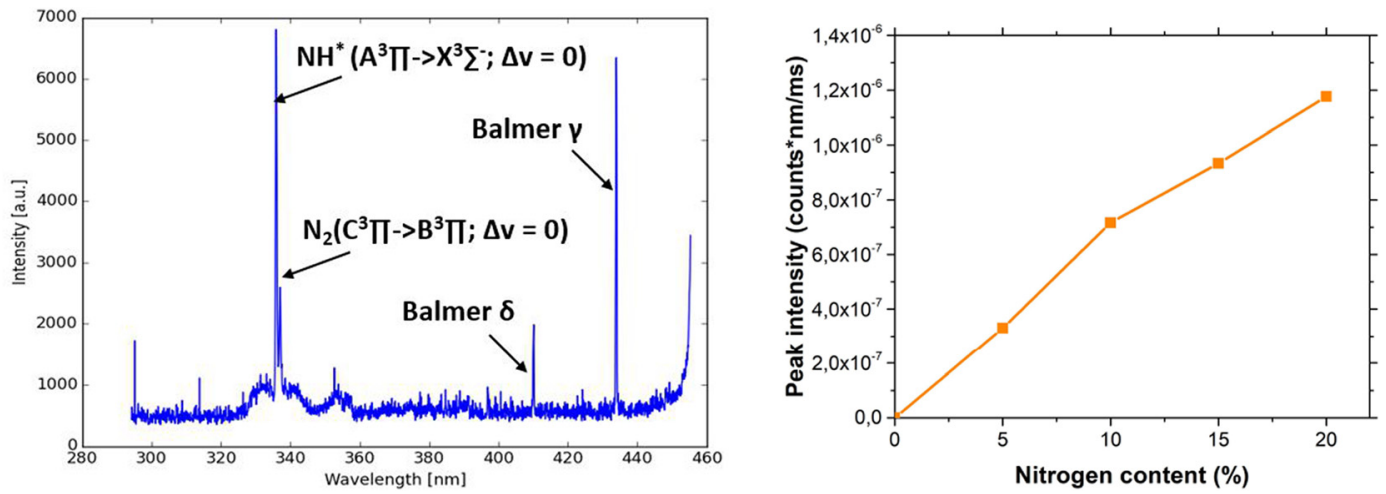

FIG. 6. (Left): Emission spectra for a $\mathrm{H}_{2}$ plasma with $\mathrm{H}_{2} / \mathrm{N}_{2}$ seeding with peak identification. (Right): Peak intensity of the $\mathrm{NH}^{*}$ band at $336 \mathrm{~nm}$ for a neutral background pressure of $2 \mathrm{~Pa}$.

channel and is calculated as follows: $P_{s}(t)=\frac{1}{S}\left(\Delta \mathrm{U}(t)+\tau \frac{\mathrm{d} \Delta \mathrm{U}(\mathrm{t})}{d t}\right){ }^{23}$ where $S$ is the sensitivity of the instrument. No substantial trend in plasma radiation is collected while increasing the content of nitrogen in the puffed gas mixture. Therefore, we shall exclude the powerlimitation effect ${ }^{28}$ (often referred to as "power starvation") that would lead to a drop in plasma pressure, basically shifting the recombination front backward from the target. The fact that no trend is observed with bolometry further suggests that the reduced heat flux and plasma pressure drop shown in Figs. 4 and 5 may be due to volume recombination processes occurring before ions reach the target.

Dedicated experiments in linear plasma machines GAMMA10/ PDX $^{29}$ and PISCES- $\mathrm{E}^{30}$ showed similar trends to the ones presented here, i.e., a synergetic effect of $\mathrm{H}_{2}+\mathrm{N}_{2}$ seeding in the recombination of hydrogen ions is observed in both cases. Plasma parameters differ substantially, with $\mathrm{T}_{\mathrm{e}}$ around $10 \mathrm{eV}$ and $\mathrm{n}_{\mathrm{e}} \approx 10^{17} \mathrm{~m}^{-3}$ in GAMMA10/ PDX and $\mathrm{T}_{\mathrm{e}}$ of about $2 \mathrm{eV}$ with $4 \times 10^{16}<\mathrm{n}_{\mathrm{e}}<3 \times 10^{17} \mathrm{~m}^{-3}$ in PISCES. Nevertheless, combining those works with this one, the effect of impurities over a wide parameter space can be studied.

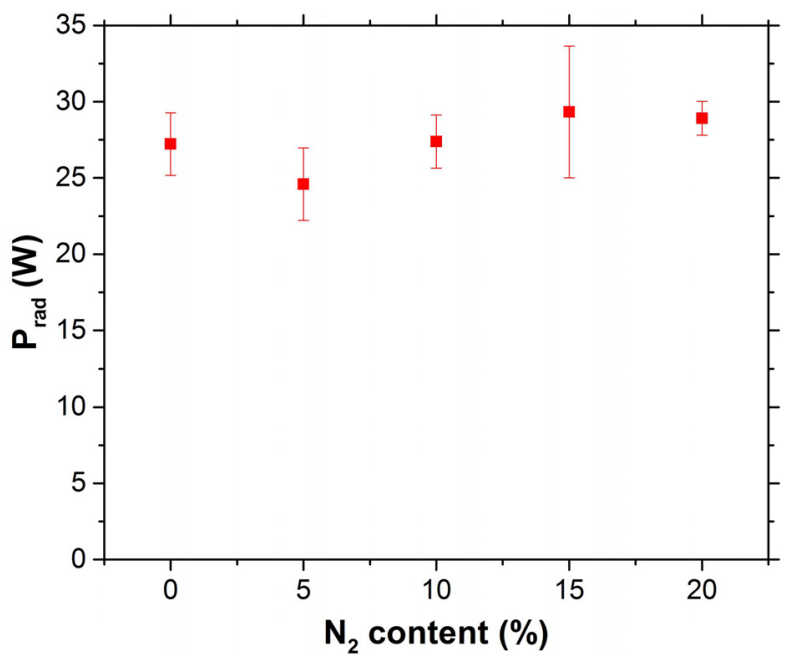

FIG. 7. Plasma radiation during the $\mathrm{H}_{2}-\mathrm{N}_{2}$ seeding scan.
In order to shed more light into the physics and the chemistry that are governing these scenarios, numerical simulations are needed. To do so, a two-step approach has been followed and details are provided in Secs. V and VI. First, volume-averaged plasma models have been setup with the aim of highlighting the most relevant plasma chemical reactions. Subsequently, these processes have been implemented in the B2.5-Eunomia coupled code. These methods are described in Secs. V and VI.

\section{GLOBAL MODEL}

Global models are zero-dimensional simulations that allow one to implement large plasma chemical data sets, given the assumption of a homogeneous distribution of species and plasma parameters throughout a defined volume. ${ }^{31}$ The simulations have been set up using the Plasimo code. ${ }^{32}$ The code solves a system of coupled differential equations: particle balance, quasineutrality, and energy balance. The adopted electron energy distribution function (EEDF) is Maxwellian. The electron energy balance is calculated as

$$
\frac{d\left(\frac{3}{2} n_{e} e T_{e}\right)}{d t}=P_{\text {input }}(t)-Q_{\text {coll }}
$$

with $e$ the elementary charge, $n_{e}$ and $T_{e}$ electron density (per cubic meter) and temperature (electron volt), $P_{\text {input }}$ the input power density, and $Q_{\text {coll }}$ the energy losses via inelastic and elastic collisions. The timeevolution of both plasma and neutral species is calculated as follows:

$$
\frac{d n_{i}}{d t}=\sum\left(s_{i}^{p}-s_{i}^{r}\right) k(t) \prod n_{i}^{s_{r}},
$$

where $s_{i}^{p}$ and $s_{i}^{r}$ are the stoichiometric coefficients of products and reactants, respectively, $k(t)$ is the reaction rate, and $n_{i}$ is the density of the species $i$. The reaction rate coefficients are written in the generalized Arrhenius form

$$
k\left(T_{e}\right)=A *\left(\frac{T_{e}}{1 e V}\right)^{n} * \exp \left(-\frac{E_{a}}{T_{e}}\right),
$$

where $A$ is declared in cubic centimeter per second and $E_{a}$ is the activation energy of the reaction, together with $T_{e}$, in electron volt. This types of codes are computationally cheaper than spatially resolved hybrid models; hence, we can implement extensive chemistry without 
implying a significant increase in the computational effort. ${ }^{33} \mathrm{~A}$ wide and detailed global model for $\mathrm{N}_{2}+\mathrm{H}_{2}$ divertor relevant plasmas, together with a full description of the code, can be found in Ref. 27. Global models have been therefore used in this study for (1) providing theoretical insights into the results achieved during detachment experiments and (2) to highlight the most relevant volume processes to be implemented into a spatially resolved coupled code.

Regarding the $\mathrm{H}_{2}+\mathrm{He}$ seeding case, in Fig. 5 we observe an increase in roughly $10 \%$ of the power load with increasing the content of $\mathrm{He}$ in the puffed gases. Such a trend is believed to be indicative of less recombination, due to dilution of molecular hydrogen. The reactions involving helium and included in the model are listed in Table I. Given that the aim of this study is to understand the influence of different impurities on plasma recombination and detachment, particular attention has been given to the recombination paths of $\mathrm{H}^{+}$and $\mathrm{H}_{2}^{+}$in the presence of He. The rate for some of the electron-induced reactions is calculated by the code by integrating the cross section over a Maxwellian electron energy distribution function (EEDF), as follows:

$$
k_{r}=\int_{E_{t}}^{\infty} \sigma_{r}(E) v(E) f(E) d(E),
$$

where $E_{t}$ is the threshold energy of the collision, $E$ is the electron energy, $f(E)$ is the EEDF, $v(E)$ is the electron thermal velocity, and $\sigma_{r}$ is the cross section of collision $r$. In the simulations, one vibrationally excited species for molecular hydrogen, namely, $\mathrm{v}=4$, and one electronically excited state for atomic helium $\left(\mathrm{He}^{*} 2^{3} \mathrm{~S}\right)$ have been included. They are important for ion conversion [reaction (7)] and two-step ionization [reactions (10) and (12)], respectively.

No mechanisms involving directly $\mathrm{H}^{+}$and He have been found in the literature. Nevertheless, the proton transfer reaction [reaction (15)] between $\mathrm{H}_{2}^{+}$and $\mathrm{He}$, followed by dissociative recombination, i.e., $\mathrm{HeH}^{+}+\mathrm{e}^{-} \rightarrow \mathrm{He}+\mathrm{H}$ [reaction (14)], constitutes a further neutralization path. Numerical results indicate that, for electron density of $\mathrm{n}_{\mathrm{e}} \approx 1 \times 10^{19} \mathrm{~m}^{-3}$ the main molecule-driven route for $\mathrm{H}_{2}^{+}$consumption is with $\mathrm{H}_{2}$, leading to the production of $\mathrm{H}_{3}^{+}$. Reaction (15) is responsible for only $5 \%$ of the total sinks of $\mathrm{H}_{2}^{+}$. With $\mathrm{n}_{\mathrm{e}} \approx 1 \times 10^{20} \mathrm{~m}^{-3}$, the main sink is entirely via dissociative recombination [reaction (8)]. The electron temperature for those simulations was $1.5 \mathrm{eV}$. A schematic representation of these results is presented in Fig. 8.

The density distribution of molecular ions in a $\mathrm{H}_{2}+\mathrm{He}$ plasma calculated with the global model is plotted in Fig. 9. In the simulation, the initial densities of $\mathrm{H}_{2}$ and $\mathrm{He}$ correspond to a 5\% impurity seeding case, i.e., $\mathrm{n}_{\mathrm{H} 2}=1 \times 10^{21} \mathrm{~m}^{-3}$ and $\mathrm{n}_{\mathrm{He}}=5 \times 10^{19} \mathrm{~m}^{-3}$. The parameter that mostly influences the population of ions in such low temperature-high density plasmas is the electron density. In Fig. 9, the amount of ions (per cubic meter) has been calculated for $n_{e}$ between $6 \times 10^{18}$ and $1 \times 10^{20} \mathrm{~m}^{-3}$. With $\mathrm{n}_{\mathrm{e}}$ below $10^{19} \mathrm{~m}^{-3}$, the dominant species is $\mathrm{H}_{3}^{+}$, which is produced via reaction (6). $\mathrm{HeH}^{+}$has a peak at $\mathrm{n}_{\mathrm{e}} \sim 2 \times 10^{19} \mathrm{~m}^{-3}$, which also corresponds to the electron density where $\mathrm{H}^{+}$becomes basically as populated as $\mathrm{H}_{3}^{+}$. When moving

TABLE I. Helium-driven plasma chemical reactions adopted in the $\mathrm{H}_{2} / \mathrm{He}$ global model.

\begin{tabular}{|c|c|c|c|}
\hline No. & Reaction & Rate $\left(\mathrm{m}^{3} \mathrm{~s}^{-1}\right)$ & References \\
\hline 1 & $\mathrm{H}_{2}+\mathrm{e}^{-} \rightarrow \mathrm{H}+\mathrm{H}+\mathrm{e}^{-}$ & From cross section & 34 \\
\hline 2 & $\mathrm{H}_{2}+\mathrm{e}^{-} \rightarrow \mathrm{H}_{2}(v=4)+\mathrm{e}^{-}$ & From cross section & 35 \\
\hline 3 & $\mathrm{H}_{2}+\mathrm{e}^{-} \rightarrow \mathrm{H}^{+}+\mathrm{H}+2 \mathrm{e}^{-}$ & $9.4 \times 10^{-16} \times T_{e}^{0.45} \times \exp \left(-\frac{29.94}{T}\right)$ & 36 \\
\hline 4 & $\mathrm{H}+\mathrm{e}^{-} \rightarrow \mathrm{H}^{+}+2 \mathrm{e}^{-}$ & From cross section & 37 \\
\hline 5 & $\mathrm{H}_{2}+\mathrm{e}^{-} \rightarrow \mathrm{H}_{2}^{+}+2 \mathrm{e}^{-}$ & From cross section & 38 \\
\hline 6 & $\mathrm{H}_{2}^{+}+\mathrm{H}_{2} \rightarrow \mathrm{H}_{3}^{+}+\mathrm{H}$ & $2 \times 10^{-15}$ & 39 \\
\hline 7 & $\mathrm{H}_{2}(v=4)+\mathrm{H}^{+} \rightarrow \mathrm{H}_{2}^{+}+\mathrm{H}$ & $2.5 \times 10^{-15}$ & 40 \\
\hline 8 & $\mathrm{H}_{2}^{+}+\mathrm{e}^{-} \rightarrow \mathrm{H}+\mathrm{H}$ & $1.6 \times 10^{-14} \times T_{e}^{-0.43}$ & 41 \\
\hline 9 & $\mathrm{H}_{3}^{+}+\mathrm{e}^{-} \rightarrow \mathrm{H}_{2}+\mathrm{H}$ & $4.36 \times 10^{-14} \times T_{e}^{-0.52}$ & 42 \\
\hline 10 & $\mathrm{He}+\mathrm{e}^{-} \rightarrow \mathrm{He}^{*}\left(2^{3} \mathrm{~S}\right)+\mathrm{e}^{-}$ & $5.05 \times 10^{-14} \times \exp \left(-\frac{22.5}{T_{e}}\right)$ & 43 \\
\hline 11 & $\mathrm{He}^{*}\left(2^{3} \mathrm{~S}\right) \rightarrow \mathrm{He}+h v$ & $6.72 \times 10^{11}$ & 43 \\
\hline 12 & $\mathrm{He}^{*}\left(2^{3} \mathrm{~S}\right)+\mathrm{e}^{-} \rightarrow \mathrm{He}^{+}+2 \mathrm{e}^{-}$ & $1.28 \times 10^{-13} \times T_{e}^{0.6} \times \exp \left(-\frac{4.78}{T_{e}}\right)$ & 43 \\
\hline 13 & $\mathrm{He}+\mathrm{e}^{-} \rightarrow \mathrm{He}^{+}+2 \mathrm{e}^{-}$ & $1.5 \times 10^{-15} \times T_{e}^{0.68} \times \exp \left(-\frac{24.6}{T_{e}}\right)$ & 43 \\
\hline 14 & $\mathrm{HeH}^{+}+\mathrm{e}^{-} \rightarrow \mathrm{He}+\mathrm{H}$ & $1.0 \times 10^{-14} \times T_{e}^{-0.6}$ & 41 \\
\hline 15 & $\mathrm{H}_{2}^{+}+\mathrm{He} \rightarrow \mathrm{HeH}^{+}+\mathrm{H}$ & $1.3 \times 10^{-16^{e}}$ & 39 \\
\hline 16 & $\mathrm{He}^{+}+\mathrm{H}_{2} \rightarrow \mathrm{He}+\mathrm{H}_{2}^{+}$ & $1.7 \times 10^{-21}$ & 39 \\
\hline 17 & $\mathrm{HeH}^{+}+\mathrm{H} \rightarrow \mathrm{He}+\mathrm{H}_{2}^{+}$ & $9.1 \times 10^{-16}$ & 39 \\
\hline 18 & $\mathrm{HeH}^{+}+\mathrm{H}_{2} \rightarrow \mathrm{He}+\mathrm{H}_{3}^{+}$ & $1.8 \times 10^{-15}$ & 39 \\
\hline 19 & $\mathrm{He}+\mathrm{e}^{-} \rightarrow \mathrm{He}+\mathrm{e}^{-}$ & From cross seciton & 44 \\
\hline
\end{tabular}




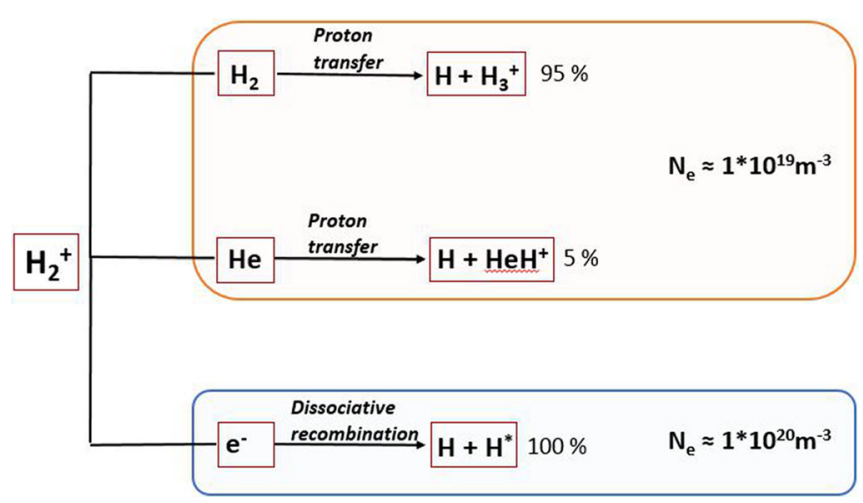

FIG. 8. Global model output of $\mathrm{H}_{2}^{+}$sink reaction paths in a $\mathrm{H}_{2} / \mathrm{He}$ plasma for two electron density scenarios. $\mathrm{T}_{\mathrm{e}}$ was $1.5 \mathrm{eV}$ in both cases.

toward higher $\mathrm{n}_{\mathrm{e}}$, dissociative recombination of $\mathrm{H}_{2}^{+}$becomes very efficient, hence a depopulation of such molecule occurs $\left(\mathrm{H}_{2}^{+}\right.$is the precursor of $\mathrm{H}_{3}^{+}$). As a result, for divertor-relevant and Magnum-PSI typical plasmas, no additional recombination effects are driven by the presence of He.

Although no beneficial effects for detachment come along the presence of $\mathrm{He}$, as it is shown experimentally and confirmed hereby by the global model, a spatially resolved code is mandatory to exclude/ include any further mechanism that could influence plasma parameters in a detachedlike scenario, such as elastic processes leading to momentum loss and/or influences on the radial transport. These simulations will be presented in Sec. VI D.

Concerning the Ar seeding cases depicted in Fig. 4, a similar behavior to the one with $\mathrm{H}_{2}+\mathrm{He}$ puffing is measured. In fact, the more argon is injected into the system, the more heat is deposited on the $\mathrm{W}$ target. The power load increases by $\approx 10 \%$ between the $0 \% \mathrm{Ar}$ and the $20 \% \mathrm{Ar}$ in the seeded mixture. This phenomenon is appointed to be again due to dilution of hydrogen molecules, reflecting in less

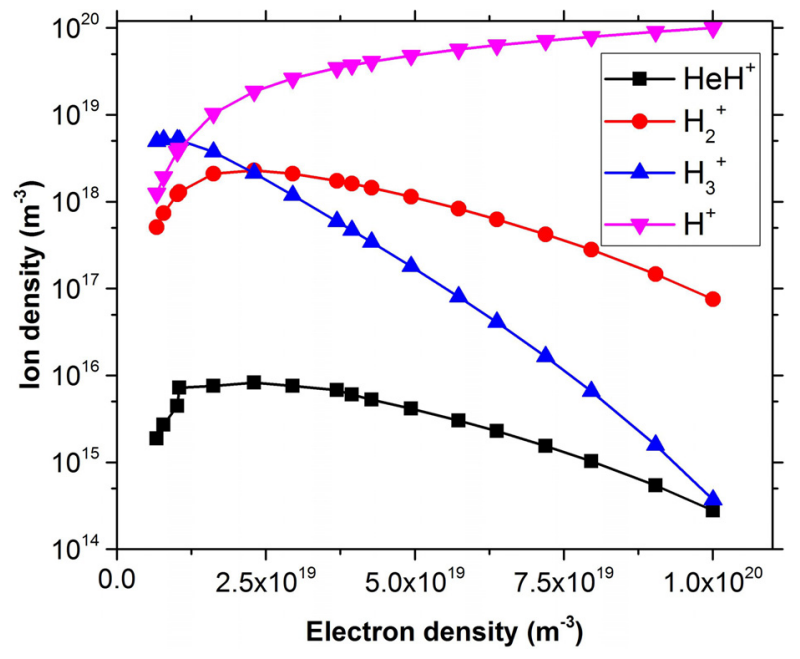

FIG. 9. Density of molecular ions as a function of $n_{e}$ calculated with PLASIMO volume recombination of the plasma, hence lowering the dissipation of ion potential before reaching the plate. In order to closely look into volume processes occurring in a hydrogen plasma with $\mathrm{H}_{2}+$ Ar seeding, another global plasma model has been created. Hydrogen-related processes are identical to the ones in Table I. An electronically excited state of $\mathrm{Ar}$, i.e., $\mathrm{Ar}^{*} 4 \mathrm{p}$, has been added being an important intermediate state for multistep ionization. Reactions are reported in Table II.

Concerning $\mathrm{H}_{2}^{+}$, for low $\mathrm{n}_{\mathrm{e}}$, proton transfer with $\mathrm{H}_{2}$ and that with $\mathrm{Ar}$ are the main sinks and account for $85 \%$ and $15 \%$ respectively, producing $\mathrm{H}_{3}^{+}$and $\mathrm{ArH}^{+}$. For Magnum-PSI-relevant plasma conditions, where $n_{e}$ is on the order of $1-5 \times 10^{20} \mathrm{~m}^{-3}, \mathrm{H}_{2}^{+}$is consumed almost entirely by dissociative recombination, while proton transfer [reaction (16)] constitutes only $5 \%$ of the total sink processes. For electron densities $\approx 1 \times 10^{19} \mathrm{~m}^{-3}$, the sources for $\mathrm{H}_{3}^{+}$are proton transfer reactions, i.e., reactions (6) and (17). The contributions are about $80 \%$ and $20 \%$, respectively. Above such a density threshold, $\mathrm{H}_{3}^{+}$is barely produced due to the very efficient dissociative recombination of its precursor $\mathrm{H}_{2}^{+}$[reaction (8)]. The main sink for $\mathrm{H}_{3}^{+}$is reaction (9) in both cases. The electron temperature is set at $1.5 \mathrm{eV}$. Argon appears to have a similar behavior to helium, in these experimental conditions. A visual representation of these plasma chemical paths is reported in Fig. 10.

It has been shown that no ion-recombination paths appear to be relevant in the presence of either Ar and He among the parameter range considered in this study. In the case of $\mathrm{N}_{2}$, however, the outcome is different. In fact, $\mathrm{N}-\mathrm{H}$ induced volume-recombination processes seem to play a crucial role in divertor-relevant detachedlike hydrogen plasma. To further study those findings, B2.5-Eunomia simulations have been carried out, aiming to provide insights into the effect of two different impurities, i.e., $\mathrm{He}$ and $\mathrm{N}_{2}$ on plasma detachment in Magnum-PSI.

\section{EUNOMIA CODE}

Eunomia is a 3D Monte Carlo code developed to model the neutral transport in linear plasma machines. ${ }^{47}$ It is conceptually very similar to the well-established code EIRENE. ${ }^{48}$ The code has been originally created to study neutrals in Pilot-PSI, ${ }^{49}$ the predecessor of Magnum-PSI. For this work, a new grid with Magnum-PSI geometry has been created and will be shown in Sec. VI A. In the code, the socalled test particles are traced: they are representative of many neutral particles. Such way of treating species is called test particle approximation method. In Eunomia standalone, the plasma equations are not solved; the plasma background is assumed to be constant and has to be provided as input. When a test particle collides with a charged or neutral particle from the background, the information regarding the obtained products and velocity distribution are stored by the code for every cycle. The new background is then updated at the beginning of the next cycle. The number of particles per cell is calculated by the code as

$$
N_{p}=\Gamma_{p} T_{a}
$$

with $\Gamma_{p}$ the influx of particles into the system (per second) and $T_{a}$ the residence time (averaged). The Boltzmann transport equation, which describes the statistical behavior of a gas or fluid, is solved by Eunomia as

$$
\mathbf{v} \cdot \nabla_{\mathbf{r}} f(\mathbf{r}, \mathbf{v}, i)=\sum C(\mathbf{r}, \mathbf{v}, i, j)+S(\mathbf{r}, \mathbf{v}, i),
$$


TABLE II. Argon-driven plasma chemical reactions adopted in the $\mathrm{H}_{2} / \mathrm{Ar}$ global model. Hydrogenic reactions adopted are the ones listed in Table I.

\begin{tabular}{|c|c|c|c|}
\hline No. & Reaction & Rate $\left(\mathrm{m}^{3} \mathrm{~s}^{-1}\right)$ & References \\
\hline 1 & $\mathrm{H}_{2}+\mathrm{e}^{-} \rightarrow \mathrm{H}+\mathrm{H}+\mathrm{e}^{-}$ & From cross section & 34 \\
\hline 2 & $\mathrm{H}_{2}+\mathrm{e}^{-} \rightarrow \mathrm{H}_{2}(v=4)+\mathrm{e}^{-}$ & From cross section & 35 \\
\hline 3 & $\mathrm{H}_{2}+\mathrm{e}^{-} \rightarrow \mathrm{H}^{+}+\mathrm{H}+2 \mathrm{e}^{-}$ & $9.4 \times 10^{-16} \times T_{e}^{0.45} \times \exp \left(-\frac{29.94}{T_{e}}\right)$ & 36 \\
\hline 4 & $\mathrm{H}+\mathrm{e}^{-} \rightarrow \mathrm{H}^{+}+2 \mathrm{e}^{-}$ & From cross section & 37 \\
\hline 5 & $\mathrm{H}_{2}+\mathrm{e}^{-} \rightarrow \mathrm{H}_{2}^{+}+2 \mathrm{e}^{-}$ & From cross section & 38 \\
\hline 6 & $\mathrm{H}_{2}^{+}+\mathrm{H}_{2} \rightarrow \mathrm{H}_{3}^{+}+\mathrm{H}$ & $2 \times 10^{-15}$ & 39 \\
\hline 7 & $\mathrm{H}_{2}(v=4)+\mathrm{H}^{+} \rightarrow \mathrm{H}_{2}^{+}+\mathrm{H}$ & $2.5 \times 10^{-15}$ & 40 \\
\hline 8 & $\mathrm{H}_{2}^{+}+\mathrm{e}^{-} \rightarrow \mathrm{H}+\mathrm{H}$ & $1.6 \times 10^{-14} \times T_{e}^{-0.43}$ & 41 \\
\hline 9 & $\mathrm{H}_{3}^{+}+\mathrm{e}^{-} \rightarrow \mathrm{H}_{2}+\mathrm{H}$ & $4.36 \times 10^{-14} \times T_{e}^{-0.52}$ & 42 \\
\hline 10 & $\mathrm{Ar}+\mathrm{e}^{-} \rightarrow \mathrm{Ar}^{+}+2 \mathrm{e}^{-}$ & $2.39 \times 10^{-14} \times T_{e}^{0.57} \times \exp \left(-\frac{17.43}{T_{e}}\right)$ & 45 \\
\hline 11 & $\operatorname{Ar}^{*}(4 \mathrm{p})+\mathrm{e}^{-} \rightarrow \operatorname{Ar}^{+}+2 \mathrm{e}^{-}$ & $1.23 \times 10^{-12} \times T_{e}^{0.25} \times \exp \left(-\frac{3.71}{T}\right)$ & 45 \\
\hline 12 & $\mathrm{Ar}^{+}+\mathrm{H}_{2} \rightarrow \mathrm{Ar}+\mathrm{H}_{2}^{+}$ & $2 \times 10^{-17}$ & 39 \\
\hline 13 & $\mathrm{Ar}^{+}+\mathrm{H}_{2} \rightarrow \mathrm{ArH}^{+}+\mathrm{H}$ & $6.7 \times 10^{-16}$ & 39 \\
\hline 14 & $\mathrm{Ar}+\mathrm{H}_{3}^{+} \rightarrow \mathrm{ArH}^{+}+\mathrm{H}_{2}$ & $3.7 \times 10^{-16}$ & 39 \\
\hline 15 & $\mathrm{Ar}+\mathrm{H}_{2}^{+} \rightarrow \mathrm{Ar}^{+}+\mathrm{H}_{2}$ & $2 \times 10^{-16}$ & 39 \\
\hline 16 & $\mathrm{Ar}+\mathrm{H}_{2}^{+} \rightarrow \mathrm{ArH}^{+}+\mathrm{H}$ & $2.1 \times 10^{-15}$ & 39 \\
\hline 17 & $\mathrm{ArH}^{+}+\mathrm{H}_{2} \rightarrow \mathrm{H}_{3}^{+}+\mathrm{Ar}$ & $6.3 \times 10^{-16}$ & 39 \\
\hline 18 & $\mathrm{ArH}^{+}+\mathrm{e}^{-} \rightarrow \mathrm{Ar}+\mathrm{H}$ & $1 \times 10^{-15}$ & 46 \\
\hline 19 & $\mathrm{Ar}+\mathrm{e}^{-} \rightarrow \mathrm{Ar}+\mathrm{e}^{-}$ & From cross section & 44 \\
\hline
\end{tabular}

where the left-hand side is the velocity vector times the probability density function $(f)$ of species $i$ in position $\mathbf{r}$ and velocity $\mathbf{v}$, $\sum C(\mathbf{r}, \mathbf{v}, i, j)$ is the collision term of inelastic and elastic collisions between neutrals and plasma particles and $S(\mathbf{r}, \mathbf{v}, i)$ is the source term. Eunomia incorporates particle sources and sinks, i.e., absorption due to pumping, conversion of ions to neutrals,

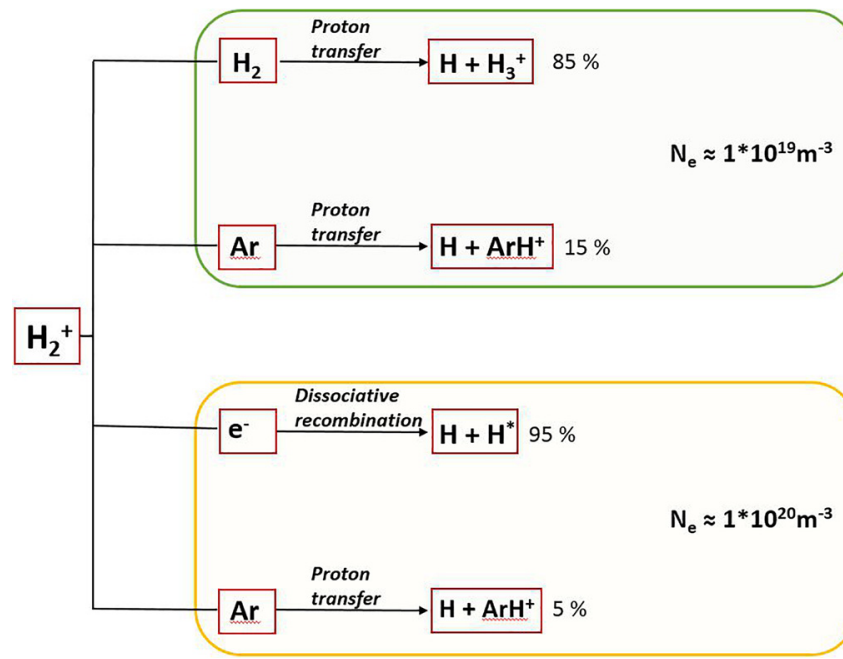

FIG. 10. Global model output of $\mathrm{H}_{2}^{+}$sink reaction paths in a $\mathrm{H}_{2} / \mathrm{Ar}$ plasma for two electron density scenarios. $\mathrm{T}_{\mathrm{e}}$ was $1.5 \mathrm{eV}$ in both cases. recycling, and gas puffing. For a more detailed overview on the theoretical background of Eunomia, the reader is referred to Ref. 50. The hydrogenic plasma chemistry contained in Eunomia is shown in Table III.

TABLE III. Hydrogen plasma chemistry included in Eunomia and suited for studying standard $\mathrm{H}_{2}$ plasma operations.

\begin{tabular}{lcc}
\hline \hline No. & Reaction & Type \\
\hline 1 & $\mathrm{H}+\mathrm{H} \rightarrow \mathrm{H}+\mathrm{H}$ & Elastic collision \\
2 & $\mathrm{H}+\mathrm{H}_{2} \rightarrow \mathrm{H}+\mathrm{H}_{2}$ & Elastic collision \\
3 & $\mathrm{H}_{2}+\mathrm{H}_{2} \rightarrow \mathrm{H}_{2}+\mathrm{H}_{2}$ & Elastic collision \\
4 & $\mathrm{H}+\mathrm{e}^{-} \rightarrow \mathrm{H}^{+}+2 \mathrm{e}^{-}$ & Ionization \\
5 & $\mathrm{H}^{+}+\mathrm{H} \rightarrow \mathrm{H}+\mathrm{H}^{+}$ & Charge exchange \\
6 & $\mathrm{H}_{2}+\mathrm{e}^{-} \rightarrow \mathrm{H}+\mathrm{H}+\mathrm{e}^{-}$ & Dissociation \\
7 & $\mathrm{H}_{2}(v)+\mathrm{e}^{-} \rightarrow \mathrm{H}_{2}(v \pm 1)+\mathrm{e}^{-}$ & Vibrational (de-)excitation \\
8 & $\mathrm{H}_{2}(v)+\mathrm{H}^{+} \rightarrow \mathrm{H}+\mathrm{H}_{2}^{+}$ & Ion conversion \\
& $\mathrm{e}^{-}+\mathrm{H}_{2}^{+} \rightarrow \mathrm{H}+\mathrm{H}_{n=2}^{*}$ & Dissociative recombination \\
& & (MAR) \\
9 & $\mathrm{H}_{2}+\mathrm{e}^{-} \rightarrow \mathrm{H}+\mathrm{H}^{-}$ & Ion conversion \\
& $\mathrm{H}^{+}+\mathrm{H}^{-} \rightarrow \mathrm{H}+\mathrm{H}_{n=3}^{*}$ & Dissociative recombination \\
& & (MAR) \\
10 & $\mathrm{H}+\mathrm{H}^{+} \rightarrow \mathrm{H}+\mathrm{H}^{+}$ & Ion-neutral elastic collision \\
11 & $\mathrm{H}_{2}+\mathrm{H}^{+} \rightarrow \mathrm{H}_{2}+\mathrm{H}^{+}$ & Ion-neutral elastic collision \\
\hline
\end{tabular}




\section{A. Coupling B2.5-EUNOMIA}

The scope of this paper is to study the effect on plasma detachment led by puffing different gas species, namely, $\mathrm{H}_{2}+\mathrm{N}_{2}$ and $\mathrm{H}_{2}$ $+\mathrm{He}$, in the target chamber. New plasma chemistry has been implemented in the code, in order to study the differences between seeding a highly reactive species (nitrogen and ammonia-related compounds) with a poorly reactive one (helium).

To provide a full description of the Magnum-PSI scenario during detachment experimental campaigns, the spatially resolved kinetic Monte Carlo code Eunomia has been coupled with the multifluid code B2.5. ${ }^{50}$ A detailed description of the code can be found in Ref. 51. The equations solved by the program are based on the Braginskii equations that are fully explained in Ref. 52 . In brief, the code solves the continuity equation for ion $i$ which is

$$
\frac{d n_{i}}{d t}+\nabla \cdot\left(n_{i} v_{i}\right)=S_{n i}
$$

with the parallel momentum equation being

$$
\begin{aligned}
\frac{d}{d t}\left(m_{i} n_{i} v_{i \|}\right)+\nabla \cdot\left(m_{i} n_{i} \mathbf{v}_{i} v_{i \|}\right)= & -\nabla_{\|} p_{i}-\left(\nabla \Pi_{i}\right)_{\|}+Z_{i} e n_{i} \nabla_{\|} \phi \\
& +F_{k}+R_{i \|}+S_{m_{i} v_{i \|}},
\end{aligned}
$$

where $-\nabla_{\|} p_{i}$ is the ion pressure gradient, $F_{k}$ is the Coriolis force, $\nabla \Pi_{i}$ is the viscosity tensor, $Z_{i} e n_{i} \nabla_{\|} \phi$ is the electric force, $R_{i \|}$ is the ion-electron friction, and $S_{m_{i} v_{i \|}}$ the ion-neutral friction. The parallel momentum balance for electrons is expressed as

$$
j_{\|}=\sigma_{\|}\left(\frac{1}{e n} \nabla_{\|} n T_{e}+\frac{0.71}{e} \nabla_{\|} T_{e}-\nabla_{\|} \phi\right)
$$

with $\sigma_{\|}$the parallel conductivity, $\frac{1}{e n} \nabla_{\|} n T_{e}$ the pressure gradient, $\frac{0.71}{e} \nabla_{\|} T_{e}$ the temperature gradient, and $\nabla_{\|} \phi$ the electric field. The definitions of radial and perpendicular current are from the sum of (ion and electron) momentum balance equations. The total energy for ions is calculated as

$$
\begin{aligned}
& \frac{d}{d t}\left(\frac{3}{2} n_{i} T_{i}+\frac{m_{i} n_{i}}{2} \mathbf{v}_{i}^{2}\right)+\nabla \cdot\left[\left(\frac{5}{2} n_{i} T_{i}+\frac{m_{i} n_{i}}{2} \mathbf{v}_{i}^{2}\right) \mathbf{v}_{\mathbf{i}}+\Pi_{i} \mathbf{v}_{i}+\mathbf{q}_{i}\right] \\
& \quad=\left(Z_{i} e n_{i} \mathbf{E}-\mathbf{R}_{i}\right) \cdot \mathbf{v}_{i}-Q_{e i}+S_{E i},
\end{aligned}
$$

while the electron energy conservation is given as
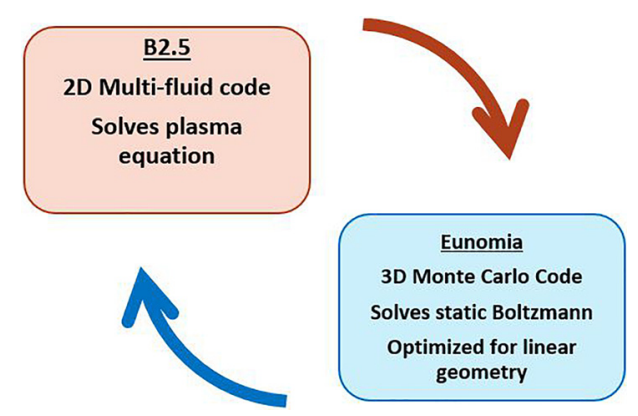

FIG. 11. Graphical representation of the iteration scheme between the two codes, reciprocally providing information on the plasma itself (B2.5 for Eunomia) and sources and sinks for particles, momentum and energy (Eunomia for B2.5).

$$
\begin{aligned}
& \frac{d}{d t}\left(\frac{3}{2} n_{e} T_{e}\right)+\nabla \cdot\left(\frac{5}{2} n_{e} T_{e} \mathbf{v}_{i}+\mathbf{q}_{e}\right) \\
& \quad=-e n_{e} \mathbf{E} \cdot \mathbf{v}_{e}+\mathbf{R}_{i} \cdot \mathbf{v}_{i}+Q_{e i}+S_{e e} .
\end{aligned}
$$

In the equations, $\mathbf{q}_{e}$ and $\mathbf{q}_{i}$ are the electron and ion energy fluxes, $Q_{e i}$ represents the coupling between electrons and ions, i.e., the collisional equilibration term, while the terms $S_{n i}, S_{m_{i} v_{i \|}}$ and $S_{E i}$ are sources for particles, momentum, and energy due to neutral and are calculated by the Monte Carlo code.

B2.5 is self-consistently coupled with Eunomia, implying that the static plasma background characterizing Eunomia standalone is now calculated and updated by B2.5 for every cycle, while Eunomia provides sources and sinks for ion and electron energy, particle density, and momentum. A graphical representation is shown in Fig. 11.

In this work, a new grid representing the upgraded linear machine Magnum-PSI has been used and can be seen in Fig. 12. All walls are reflecting walls for the test particle, and the velocity of the

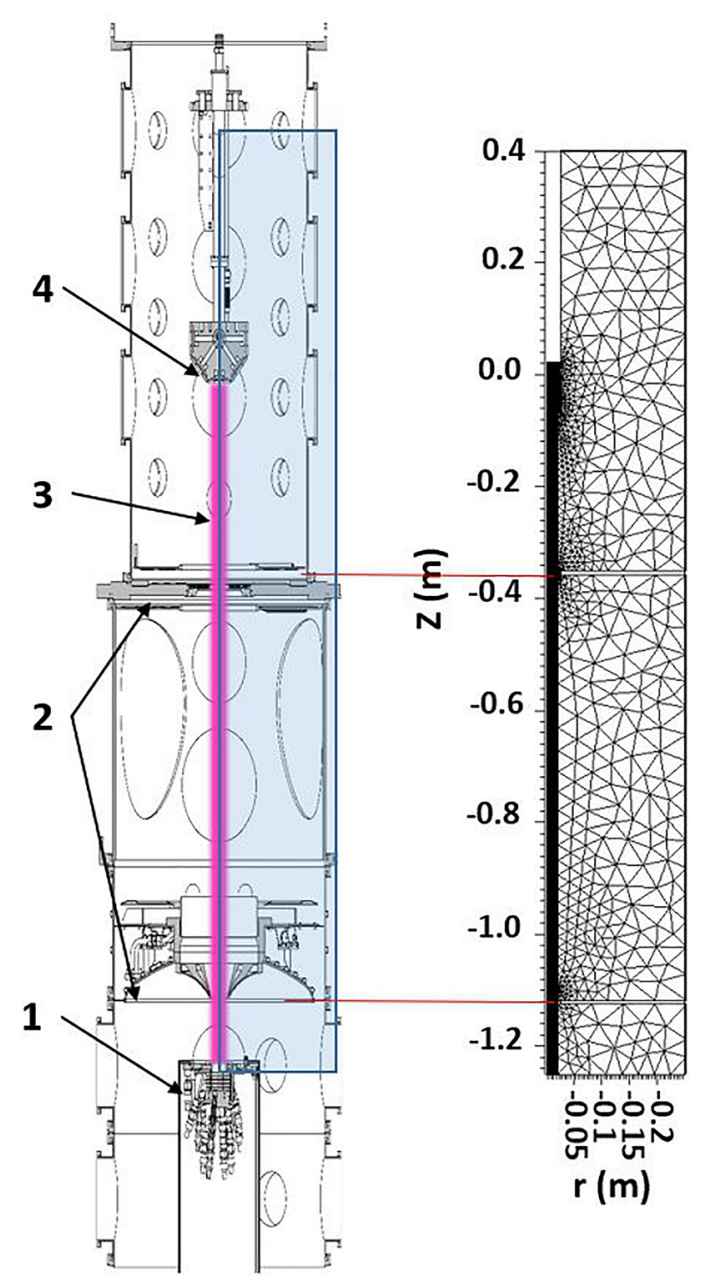

FIG. 12. (Right): Drawing of Magnum-PSI, where (1) is the plasma source, (2) the skimmers, (3) the plasma beam, and (4) the target. On the left, the geometry used in the simulations of the couple codes is shown. 
reflected particle follows a cosine distribution. Moreover, the outer walls thermalize the reflected particle; therefore, the velocity is rescaled to the wall temperature. The skimmers do not thermalize the particle. Differential pumping is treated in the code as follows: a certain probability rate describes whether the test particle is terminated when crossing this boundary is specified. If that would not be the case, it gets reflected. The probability rate is updated each cycle according to the specified pressure in a specified location within the domain. To achieve the differential pumping, we have different pumps in different locations for each of the pumps.

\section{B. Implementation of the codes}

The implemented processes regarding $\mathrm{N}_{2}-\mathrm{H}_{2}$ are listed in Table IV. To get to such a reduced scheme, an extensive global plasma model has been first made. An internal validation of the code, implying a quantitative comparison of the species densities between the fully extended model with the reduced one, has been carried out for three different cases of study. Plasma scenarios were set at $\mathrm{T}_{\mathrm{e}}(1)=0.8 \mathrm{eV}$ and $\mathrm{n}_{\mathrm{e}}(1)=6 \times 10^{19} \mathrm{~m}^{-3}, \mathrm{~T}_{\mathrm{e}}(2)=1.2 \mathrm{eV}$ and $\mathrm{n}_{\mathrm{e}}(2)=2.6 \times 10^{20} \mathrm{~m}^{-3}$, and $\mathrm{T}_{\mathrm{e}}(3)=1.8 \mathrm{eV}$ and $\mathrm{n}_{\mathrm{e}}(3)=3.5 \times 10^{20} \mathrm{~m}^{-3}$ respectively. Results clearly showed consistency between the two sets. More details on such

TABLE IV. Processes included in B2.5-Eunomia to study nitrogen-seeding hydrogen plasma detachment scenarios.

\begin{tabular}{|c|c|c|c|}
\hline No. & Reaction & Type & References \\
\hline 12 & $\mathrm{~N}_{2}+\mathrm{e}^{-} \rightarrow \mathrm{N}+\mathrm{N}+\mathrm{e}^{-}$ & Dissociation & 53 \\
\hline 13 & $\mathrm{H}_{2}+\mathrm{N} \rightarrow \mathrm{NH}+\mathrm{H}$ & Atomic transfer & 54 \\
\hline 14 & $\mathrm{~N}_{2}+\mathrm{H}_{2}^{+} \rightarrow \mathrm{N}_{2} \mathrm{H}^{+}+\mathrm{N}$ & Proton transfer & 39 \\
\hline 15 & $\mathrm{~N}_{2} \mathrm{H}^{+}+\mathrm{e}^{-} \rightarrow \mathrm{N}_{2}+\mathrm{H}$ & $\begin{array}{l}\text { Dissociative } \\
\text { recombination }\end{array}$ & 55 \\
\hline 16 & $\mathrm{~N}_{2} \mathrm{H}^{+}+\mathrm{e}^{-} \rightarrow \mathrm{NH}+\mathrm{N}$ & $\begin{array}{l}\text { Dissociative } \\
\text { recombination }\end{array}$ & 55 \\
\hline 17 & $\mathrm{~N}+\mathrm{e}^{-} \rightarrow \mathrm{N}^{+}+2 \mathrm{e}^{-}$ & Ionization & 56 \\
\hline 18 & $\begin{array}{c}\mathrm{NH}+\mathrm{H}^{+} \rightarrow \mathrm{NH}^{+}+\mathrm{H} \\
\mathrm{NH}^{+}+\mathrm{e}^{-} \rightarrow \mathrm{N}+\mathrm{H}\end{array}$ & $\begin{array}{l}\text { Ion conversion } \\
\text { Dissociative } \\
\text { recombination } \\
\text { (N-MAR) }\end{array}$ & $\begin{array}{l}57 \\
41\end{array}$ \\
\hline 19 & $\mathrm{~N}+\mathrm{e}^{-} \rightarrow \mathrm{N}+\mathrm{e}^{-}$ & Elastic collision & BGK \\
\hline 20 & $\mathrm{~N}_{2}+\mathrm{e}^{-} \rightarrow \mathrm{N}_{2}+\mathrm{e}^{-}$ & Elastic collision & BGK \\
\hline 21 & $\mathrm{NH}+\mathrm{H}_{2} \rightarrow \mathrm{NH}+\mathrm{H}_{2}$ & Elastic collision & BGK \\
\hline 22 & $\mathrm{NH}+\mathrm{H} \rightarrow \mathrm{NH}+\mathrm{H}$ & Elastic collision & BGK \\
\hline 23 & $\mathrm{NH}+\mathrm{N}_{2} \rightarrow \mathrm{NH}+\mathrm{N}_{2}$ & Elastic collision & BGK \\
\hline 24 & $\mathrm{NH}+\mathrm{N} \rightarrow \mathrm{NH}+\mathrm{N}$ & Elastic collision & BGK \\
\hline 25 & $\mathrm{H}_{2}+\mathrm{H}_{2} \rightarrow \mathrm{H}_{2}+\mathrm{H}_{2}$ & Elastic collision & BGK \\
\hline 26 & $\mathrm{H}_{2}+\mathrm{N}_{2} \rightarrow \mathrm{H}_{2}+\mathrm{N}_{2}$ & Elastic collision & BGK \\
\hline 27 & $\mathrm{~N}_{2}+\mathrm{N}_{2} \rightarrow \mathrm{N}_{2}+\mathrm{N}_{2}$ & Elastic collision & BGK \\
\hline 28 & $\mathrm{H}+\mathrm{N} \rightarrow \mathrm{H}+\mathrm{N}$ & Elastic collision & BGK \\
\hline 29 & $\mathrm{H}+\mathrm{H} \rightarrow \mathrm{H}+\mathrm{H}$ & Elastic collision & BGK \\
\hline 30 & $\mathrm{~N}+\mathrm{N} \rightarrow \mathrm{N}+\mathrm{N}$ & Elastic collision & BGK \\
\hline 31 & $\mathrm{~N}+\mathrm{N}_{2} \rightarrow \mathrm{N}+\mathrm{N}_{2}$ & Elastic collision & BGK \\
\hline 32 & $\mathrm{H}_{2}+\mathrm{N} \rightarrow \mathrm{H}_{2}+\mathrm{N}$ & Elastic collision & BGK \\
\hline 33 & $\mathrm{~N}_{2}+\mathrm{H} \rightarrow \mathrm{N}_{2}+\mathrm{H}$ & Elastic collision & BGK \\
\hline
\end{tabular}

TABLE V. Processes included in B2.5-Eunomia to study helium-seeding hydrogen plasma detachment scenarios.

\begin{tabular}{cccc}
\hline \hline No. & Reaction & Type & References \\
\hline 34 & $\mathrm{He}+\mathrm{e}^{-} \rightarrow \mathrm{He}^{*}\left(2^{3} \mathrm{~S}\right)+\mathrm{e}^{-}$ & Excitation & 58 \\
35 & $\mathrm{He}^{*}\left(2^{3} \mathrm{~S}\right) \rightarrow \mathrm{He}+h v$ & Radiative relaxation & 58 \\
36 & $\mathrm{He}^{*}\left(2^{3} \mathrm{~S}\right)+\mathrm{e}^{-} \rightarrow \mathrm{He}^{+}+2 \mathrm{e}^{-}$ & Ionization & 58 \\
37 & $\mathrm{He}+\mathrm{e}^{-} \rightarrow \mathrm{He}^{+}+2 \mathrm{e}^{-}$ & Ionization & 58 \\
38 & $\mathrm{He}^{+}+\mathrm{e}^{-} \rightarrow \mathrm{He}$ & Recombination & 56 \\
39 & $\mathrm{He}+\mathrm{e}^{-} \rightarrow \mathrm{He}+\mathrm{e}^{-}$ & Elastic collision & BGK \\
40 & $\mathrm{He}+\mathrm{H}_{2} \rightarrow \mathrm{He}+\mathrm{H}_{2}$ & Elastic collision & BGK \\
41 & $\mathrm{He}+\mathrm{H} \rightarrow \mathrm{He}+\mathrm{H}$ & Elastic collision & BGK \\
42 & $\mathrm{He}+\mathrm{H}^{+} \rightarrow \mathrm{He}+\mathrm{H}^{+}$ & Elastic collision & BGK \\
\hline \hline
\end{tabular}

a procedure can be found in Ref. 27. It is worth mentioning that the plasma chemical tables presented hereafter have been implemented keeping the ones in Table III fully activated.

For what concerns simulations regarding $\mathrm{He} / \mathrm{H}_{2}$ puffing in the target chamber, other processes have been added in the code. These are listed in Table $\mathrm{V}$.

Finally, the reactions implemented for the $\mathrm{H}_{2} /$ Ar seeding case are reported in Table VI.

In B2.5-Eunomia, the rate for hydrogenic collisions has been taken from AMJUEL ${ }^{56}$ and HYDEL databases, which are the ones also used by default in the Eirene code. For the newly added reactions, the reference for the rate is listed. The cross section for neutral-neutral elastic collisions is calculated by using the BGK approximation $\operatorname{method}^{59}$ and is based on the Lennard-Jones potential. For electrondriven processes, the rate is calculated by the code as a function of the local (per-cell) electron temperature and density. Molecule-assistedrecombination mechanisms, i.e., reactions (8), (9), and (17) are treated in such a way that the rate-determining step is the ion conversion. The products of that process are assumed to instantaneously recombine with an electron.

\section{Simulating plasma detachment in Magnum-PSI by means of B2.5-Eunomia codes}

In this section, we present numerical simulations concerning the modeling of the full geometry of linear machine Magnum-PSI. For the first time, couple codes B2.5 and Eunomia have been used to specifically study detachedlike experimental scenarios with newly

TABLE VI. Processes included in B2.5-Eunomia to study Argon-seeding hydrogen plasma detachment scenarios.

\begin{tabular}{lccc}
\hline \hline No. & Reaction & Type & References \\
\hline 43 & $\mathrm{Ar}+\mathrm{e}^{-} \rightarrow \mathrm{Ar}^{+}+2 \mathrm{e}^{-}$ & Excitation & 56 \\
44 & $\mathrm{Ar}^{+}+\mathrm{e}^{-} \rightarrow \mathrm{Ar}$ & Recombination & 56 \\
45 & $\mathrm{Ar}+\mathrm{Ar} \rightarrow \mathrm{Ar}+\mathrm{Ar}$ & Elastic collision & BGK \\
46 & $\mathrm{Ar}+\mathrm{H} \rightarrow \mathrm{Ar}+\mathrm{H}$ & Elastic collision & BGK \\
47 & $\mathrm{Ar}+\mathrm{H}_{2} \rightarrow \mathrm{Ar}+\mathrm{H}_{2}$ & Elastic collision & BGK \\
48 & $\mathrm{Ar}+\mathrm{H}^{+} \rightarrow \mathrm{Ar}+\mathrm{H}^{+}$ & Elastic collision & BGK \\
\hline \hline
\end{tabular}


implemented plasma chemistry. The scope of this exercise is to gain more knowledge on the physics and chemistry occurring during experiments. The authors would like to underline that these simulations have to be considered as code experiments rather than predictive models to be quantitatively benchmarked with experimental data.

\section{Modeling results}

The baseline scenario, i.e., attached plasma conditions, have been set up without any external neutral source (gas puffing) and the achieved background neutral pressure in the target chamber corresponds to $\approx 0.3 \mathrm{~Pa}$. As can be seen in Fig. 13(a), the plasma beam is conserved throughout its whole path in the target chamber. In particular, we can observe a peak in the electron density in the vicinity of the target. This is due to ion recycling at the wall, which leads to desorption of neutrals that are promptly ionized. In attached plasma conditions, the plasma environment near the wall is in the so-called high recycling regime. Similar findings have been described in Ref. 60, where simulations with SOLEDGE2D-EIRENE ${ }^{61}$ suite have been carried out for linear plasma device Pilot-PSI.

In Fig. 13(b), a detached plasma scenario has been obtained by actively puffing $\mathrm{H}_{2}$ in the target chamber. The resulting background neutral pressure is $\approx 2 \mathrm{~Pa}$. The seeding location is depicted by the red circle in Fig. 13. The "gaseous chamber" concept, which has been experimentally studied with several linear machines, as described in Ref. 16, has been successfully replicated in this simulation. As can be observed, $\mathrm{n}_{\mathrm{e}}$ quickly drops once the beam enters the target chamber, passing from $\approx 5 \times 10^{19} \mathrm{~m}^{-3}$ to $\approx 1 \times 10^{19} \mathrm{~m}^{-3}$. A further

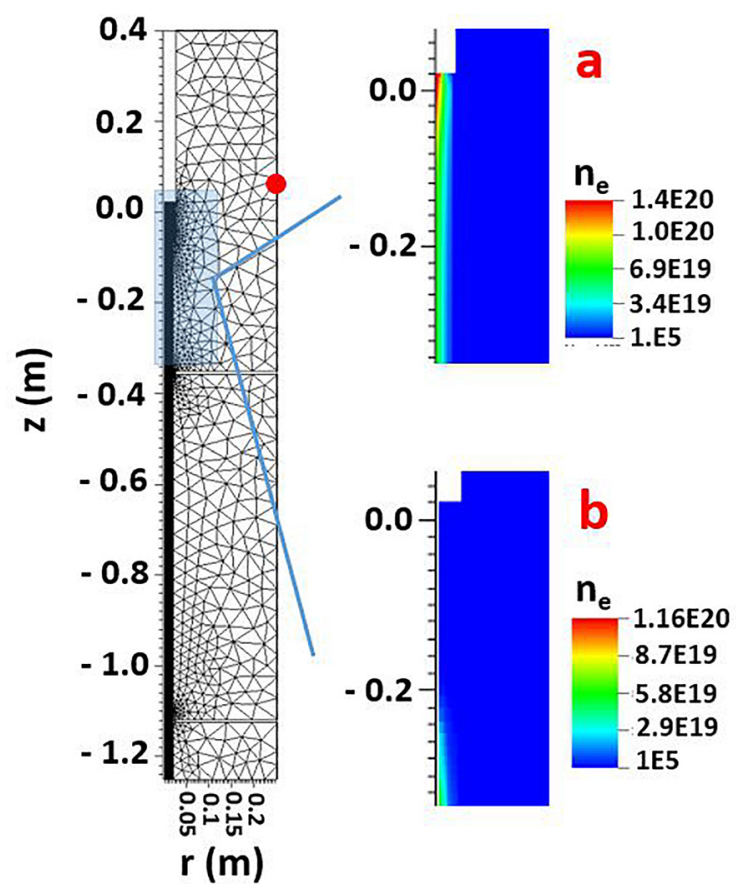

FIG. 13. Comparison between attached (a) and detached (b) plasma scenarios. On the left, the highlighted region (in blue) corresponds to the volume between the skimmer and the target. The red circle is the puffing location in the simulations. characteristic feature of detachment, compared to the attached case, is the plasma pressure drop led by momentum loss and volume recombination processes.

Dedicated code-experiments have been carried out in order to study the difference between $\mathrm{He}, \mathrm{Ar}$, and $\mathrm{N}_{2}$ puffing, together with $\mathrm{H}_{2}$, at different mixing ratios. In principle, we replicated the experiments presented in Sec. IV. The novelty of this exercise lays in the fact that new plasma chemical processes have been included in a kinetic-fluid coupled code. The aim is to highlight possible different volume-driven effects on plasma detachment. In particular, the role of the reactive $\mathrm{N}_{2}$-related $\mathrm{NH}$ radical and N-MARs is of great interest, given that $\mathrm{NH}_{\mathrm{x}}$ molecules are surely produced in the divertor. The particle source for $\mathrm{NH}$ has been set assuming a conversion efficiency of nitrogen to ammonia (molecular precursor for the $\mathrm{NH}$ radical) of 7\%, which is in line with previous studies. ${ }^{62,63} \mathrm{NH}_{\mathrm{x}}$ particles are formed via the surface process; while $\mathrm{N}_{2}$ is injected in the location depicted in Fig. 13, the source for $\mathrm{NH}$ has been set at the target plate.

The total plasma pressure modeled at $3 \mathrm{~cm}$ in front of the target, together with the heat flux (at the sheath entrance) calculated as in Eq. (1), is reported in Fig. 14.

Plasma parameters achieved with the simulations are about on the order of $\mathrm{n}_{\mathrm{e}} \approx 10^{19} \mathrm{~m}^{-3}$ with electron temperatures below $1 \mathrm{eV}$. Although a quantitative comparison between experiments and simulations is beyond the scope of this work, the same trend is obtained when comparing Magnum-PSI results with the model.

The presence of nitrogen seeding in combination with $\mathrm{H}_{2}$ leads to a net decrease in the plasma pressure by roughly $35 \%$. This value may be overestimated due to the fact that $\mathrm{NH}$ (electron donor responsible for the first step of N-MAR) is injected entirely from the surface of the target. Regarding $\mathrm{H}_{2}+\mathrm{Ar}$ and $\mathrm{H}_{2}+\mathrm{He}$ puffing scenarios, a reversed effect is achieved. In fact, plasma pressure increases by $\approx 20 \%$ in both cases, reducing the effectiveness of detachment. No significant differences are recorded between $\mathrm{He}$ and Ar scans, indicating that the absence of impurity-induced volume recombination processes might lead to a dilution effect of $\mathrm{H}_{2}$ in the plasma parameter range characterizing these simulations. The heat flux, calculated at the sheath edge with no presheath or sheath effects taken into account, provided the same trend. It is worth underlining that a full description of the sheath physics is beyond the capabilities of B2.5. No significant plasma radial transport occurs along the different scans for $\mathrm{He}, \mathrm{Ar}$, and $\mathrm{N}_{2}$ cases of study.

These results confirm that adding inert species into the puffed mixture does not have beneficial effects for detachment in the vicinity of the target. An increase in plasma pressure leads to an enhanced particle flux, hence to a higher heat flux to the target.

To address the contribution of N-MAR and MAR, respectively, the collision frequency of these recombination processes for a $10 \% \mathrm{~N}_{2}$ seeding case has been monitored and is shown in Fig. 15.

The N-MAR process occurs extensively in the vicinity of the target (axially) and radially along the whole beam, while it becomes negligible when moving far away from the plate at about $5 \mathrm{~cm}$. The spatial distribution of such process represents a clear indication of the enhanced recombination of incoming hydrogen ions before they reach the target.

Regarding the purely hydrogenic process, hardly any MAR events appear to be occurring in the simulation. The vibrational excited states of $\mathrm{H}_{2}$, which are needed for the first ion conversion step of MAR, are 

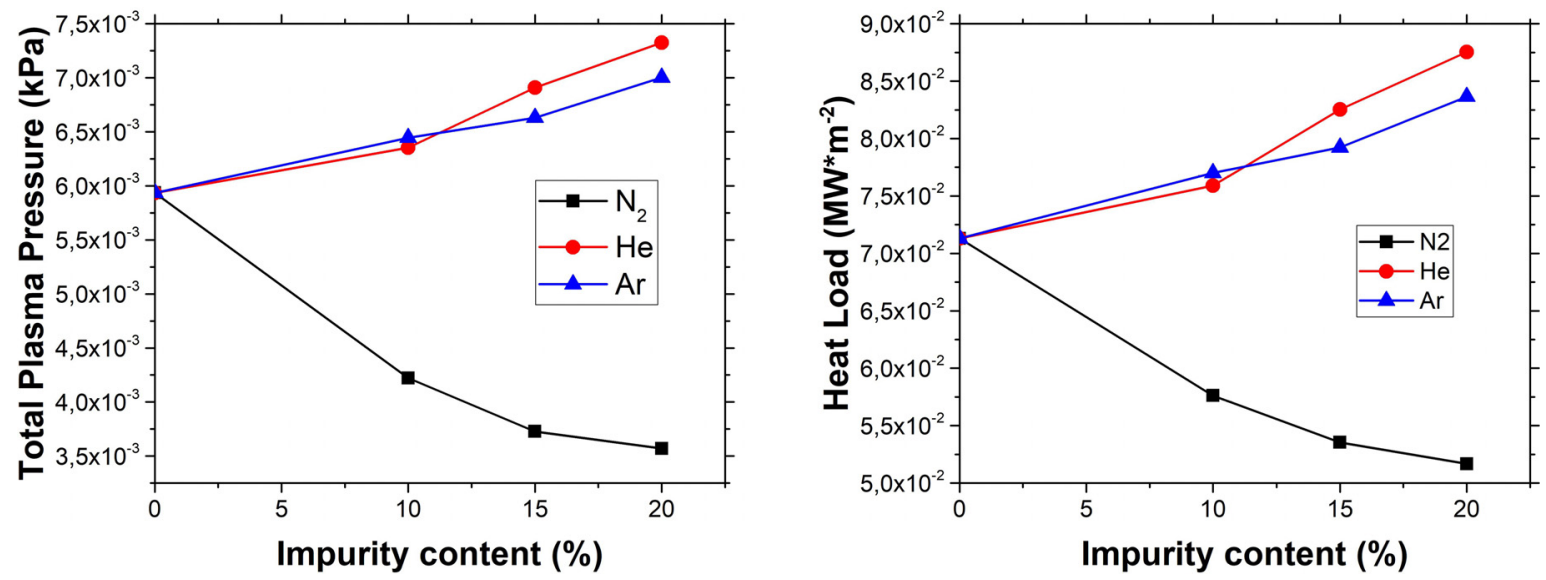

FIG. 14. Left: Modeled total plasma pressure. Right: heat load.

simulated in the code. Nevertheless, the contribution of this two-step reaction does not seem to be relevant in the conditions examined. That might be due to the low $\mathrm{T}_{\mathrm{e}}(<1 \mathrm{eV})$, which is given by the code as an output.

The main lack of this model and, to the knowledge of the authors, of any other $\mathrm{H}_{2}-\mathrm{N}_{2}$ plasma code, is the absence of a scaling law for the following process: $\mathrm{H}^{+}+\mathrm{N}_{2}(\mathrm{v}) \rightarrow \mathrm{H}+\mathrm{N}_{2}^{+}$, which is a further recombination path for $\mathrm{H}^{+}$. It is fair to assume that a large fraction of injected $\mathrm{N}_{2}$ molecules undergo electron-impact vibrational excitation [threshold energy for $\mathrm{N}_{2}(\mathrm{v}=0->\mathrm{v}=1)$ is $0.29 \mathrm{eV}$ ]. To provide a description of the entire plasma chemistry going on in a detachedlike hydrogen plasma with $\mathrm{N}_{2}$ seeding, and therefore to make quantitative predictions, a dedicated study on the role of $\mathrm{N}_{2}(\mathrm{v})$ would be needed.

Moreover, to carry out quantitative comparison between experiments and simulations with B2.5-Eunomia, dedicated studies on the "free parameters" currently assumed in the code, e.g., cross field transport coefficients, potential boundary, and plasma flow from the source should be carried out. Nevertheless, the newly implemented plasma chemistry is responsible for the achieved trends, indicating that the presence (or the absence) of further ion-recombination paths, that differ from the pure hydrogenic ones, may have positive influence in reducing the particle flux during detachment. Specifically, the role of N-MAR is hereby highlighted experimentally and confirmed with numerical
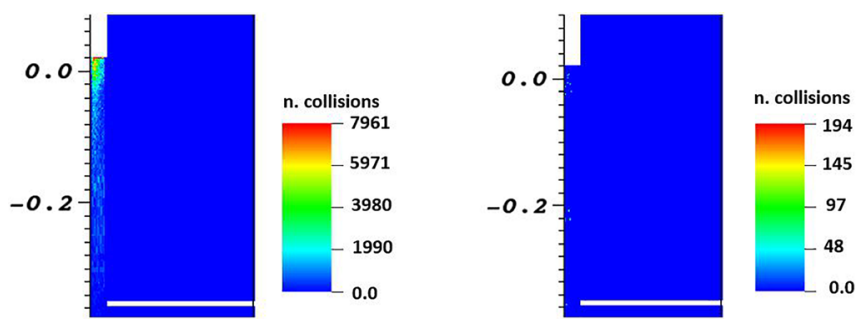

FIG. 15. N-MAR (left) and MAR (right) collision frequency. simulations. Therefore, that process should be included in the state-of-the-art divertor-relevant plasma physics codes.

\section{CONCLUSIONS AND OUTLOOK}

The effect of different impurities on plasma detachment has been studied by means of both experiments and numerical simulations. Experiments highlighted the beneficial role of $\mathrm{N}_{2}$, seeded together with $\mathrm{H}_{2}$ in the target chamber, compared to $\mathrm{He}+\mathrm{H}_{2}$ and $\mathrm{Ar}+\mathrm{H}_{2}$, which showed an opposite trend. In the $\mathrm{N}_{2}$-seeding case, a plasma pressure decrease and a reduced heat load collected at the target plate are observed, while in the remaining two cases, i.e., Ar and He, detachment performance is lowered. The plasma chemistry occurring in divertor-relevant plasma detached scenarios has been studied by means of global plasma modeling and the subsequent reduced sets of chemical equations have been implemented in the coupled code B2.5Eunomia. Simulation results qualitatively reproduce the experimental findings, confirming the relevance of $\mathrm{N}$-induced volume recombination processes (N-MAR). Moreover, a comparison between the wellknown hydrogenic MAR and N-MAR has been performed, pointing out the significance of the latter in converting hydrogen ions to neutrals via molecule-assisted process. Nitrogen-related volume processes should thus be included in divertor and plasma-edge codes, N-MAR being an efficient route for the neutralization of hydrogen ions.

In the perspective of a detached plasma in a tokamak, this study focuses on the last portion of the SOL, between the ionization front and the divertor plate. A one-to-one comparison between a linear plasma device and a real divertor might be misleading. Nevertheless, results presented in this work show a heat flux reduction of about $20 \%$, compared to pure $\mathrm{H}_{2}$, when nitrogen (and therefore $\mathrm{N}-\mathrm{MAR}$ ) is introduced in the simulated environment.

Concerning these species in ITER, one of the crucial issues is the formation of tritiated ammonia, where tritium atoms bond with nitrogen and are, therefore, taken out from the system. Although no ultimate solution of such a problem has been given so far, a possibility to recover tritium might be by applying a catalytic reactor suited for isotope exchange processes at the end of the divertor pump. In this way, tritium might be recovered and could, subsequently, be re-emitted in the plasma. 


\section{ACKNOWLEDGMENTS}

This work has been carried out within the framework of the EUROfusion Consortium and has received funding from the Euratom research and training program 2014-2018 and 2019-2020 under Grant Agreement No. 633053. The views and opinions expressed herein do not necessarily reflect those of the European Commission.

\section{REFERENCES}

${ }^{1}$ R. A. Pitts et al., "Physics basis and design of the ITER plasma-facing components," J. Nucl. Mater. 415(1 SUPPL), S957-S964 (2011).

${ }^{2}$ P. Stangeby, The Plasma Boundary of Magnetic Fusion Devices (Institute of Physics Publishing, 2000).

${ }^{3}$ S. I. Krasheninnikov, A. Pigarov, and T. K. Soboleva, "Plasma-neutral gas interaction in a tokamak divertor: Effects of hydrogen molecules and plasma recombination," J. Nucl. Mater. 241-243, 283-287 (1997).

${ }^{4} \mathrm{G}$. DeTemmerman, "Plasma-surface interactions under high heat and particle fluxes," Acta Polytech. 53(2), 142-147 (2013).

${ }^{5}$ S. I. Krasheninnikov, A. S. Kukushkin, and A. A. Pshenov, "Divertor plasma detachment," Phys. Plasmas 23(5), 055602 (2016).

${ }^{6}$ A. Loarte et al., "Chapter 4: Power and particle control," Nucl. Fusion 47(6), S203-S263 (2007)

${ }^{7}$ Y. U. S. Takamura, N. Ohno, and D. Nishijima, "Generation and characteristics of detached recombining plasma and its dynamic behaviour a bridge between fusion plasmas and low-temperature ionized gases," J. Nucl. Mater. 313-316(1), A42-A48 (2002).

${ }^{8}$ Y. Hayashi, "Plasma detachment study of high density helium plasmas in the Pilot-PSI device,” Nucl. Fusion 56, 126006 (2016).

${ }^{9}$ D. E. Post, "A review of recent developments in atomic processes for divertors and edge plasmas,” J. Nucl. Mater. 220-222, 143-157 (1995).

${ }^{10}$ A. A. Pshenov, A. S. Kukushkin, and S. I. Krasheninnikov, "Energy balance in plasma detachment," Nucl. Mater. Energy 12, 948-952 (2017).

${ }^{11}$ A. Loarte, R. D. Monk, and J. R. Mart, "Plasma detachment in JET Mark I divertor experiments," Nucl. Fusion 38, 331 (1998).

${ }^{12} \mathrm{O}$. Gruber et al., "Observation of continuous divertor detachment in H-mode discharges in ASDEX Upgrade,” Phys. Rev. Lett. 74(21), 4217-4220 (1995).

${ }^{13} \mathrm{M}$. Oberkofler et al., "First nitrogen-seeding experiments in JET with the ITERlike wall,” J. Nucl. Mater. 438(SUPPL), S258-S261 (2013).

${ }^{14}$ A. Kallenbach et al. "Plasma surface interactions in impurity seeded plasmas," J. Nucl. Mater. 415(1 Suppl), S19-S26 (2011).

${ }^{15}$ A. Kallenbach, M. Bernert, R. Dux, L. Casali, T. Eich, and L. Giannone, "Impurity seeding for tokamak power exhaust: From present devices via ITER to DEMO," Plasma Phys. Controlled Fusion 55, 124041 (2013).

${ }^{16} \mathrm{~N}$. Ohno, "Plasma detachment in linear devices," Plasma Phys. Controlled Fusion 59(3), 034007 (2017).

${ }^{17}$ H. J. N. Van Eck et al., "High-fluence and high flux performance characteristics of the superconducting Magnum-PSI linear plasma facility," Fusion Eng. Des. 142, 26-32 (2019).

${ }^{18} \mathrm{~J}$. Rapp et al., "Construction of the plasma-wall experiment Magnum-PSI," Fusion Eng. Des.. 85(7-9), 1455-1459 (2010).

${ }^{19} \mathrm{~T}$. W. Morgan et al., "A high-repetition rate edge localised mode replication system for the Magnum-PSI and Pilot-PSI linear devices," Plasma Phys, Controlled Fusion 56, 095004 (2014).

${ }^{20} \mathrm{G}$. J. Van Rooij et al., "Extreme hydrogen plasma densities achieved in a linear plasma generator,” Appl. Phys. Lett. 90(12), 121501 (2007).

${ }^{21}$ H. J. N. Van Eck et al., "Pre-design of Magnum-PSI: A new plasma-Wall interaction experiment," Fusion Eng. Des. 82, 1878-1883 (2007).

${ }^{22}$ G. J. Van Rooij, “Thomson scattering at Pilot-PSI and Magnum-PSI," Plasma Phys. Controlled Fusion 51, 124037 (2009).

${ }^{23}$ G. G. Van Eden et al., "Plasma radiation studies in Magnum-PSI using resistive bolometry," Nucl. Fusion 58(10), 106006 (2018).

${ }^{24} \mathrm{~A}$. Schumack, "The influence of electric fields and neutral particles on the plasma sheath at ITER divertor conditions," Ph.D. thesis (Eindhoven University of Technology, 2011).
${ }^{25} \mathrm{~T}$. Body et al., "A volume-averaged model of nitrogen-hydrogen plasma chemistry to investigate ammonia production in a plasma-surface-interaction device," Plasma Phys. Controlled Fusion. 60(7), 075011 (2018).

${ }^{26} \mathrm{R}$. Perillo et al., "Experimental evidence of enhanced recombination of a hydrogen plasma induced by nitrogen seeding in linear device Magnum-PSI," Nucl. Mater. Energy 19, 87-93 (2019).

${ }^{27} \mathrm{R}$. Perillo et al., "Studying the influence of nitrogen seeding in a detached-like hydrogen plasma by means of numerical simulations," Plasma Phys. Controlled Fusion 60(10), 105004 (2018).

${ }^{28} \mathrm{~K}$. Verhaegh, Spectroscopic Investigations of Detachment on TCV (University of York, 2018).

${ }^{29} \mathrm{~N}$. Ezumi et al., "Synergistic effect of nitrogen and hydrogen seeding gases on plasma detachment in the GAMMA 10/PDX tandem mirror," Nucl. Fusion 59, 066030 (2019)

${ }^{30}$ S. Abe, S. C. Thakur, R. P. Doerner, and G. R. Tynan, "Hydronitrogen molecular assisted recombination (HN-MAR) process in ammonia seeded deuterium plasmas," Nucl. Mater. Energy 19, 390-396 (2019).

${ }^{31}$ A. Hurlbatt et al., "Concepts, capabilities, and limitations of global models: A review,” Plasma Processes Polym. 14(1), 1600138 (2017).

${ }^{32}$ J. Van Dijk, K. Peerenboom, M. Jimenez, D. Mihailova, and J. Van Der Mullen, “The plasma modelling toolkit Plasimo," J. Phys. D: Appl. Phys 42(19), 194012 (2009).

${ }^{33}$ W. Graef, "Zero-Dimensional Models for Plasma Chemistry," Ph.D. thesis (Eindhoven University of Technology, 2012).

${ }^{34} \mathrm{~J}$.-S. Yoon et al., "Cross sections for electron collisions with hydrogen molecules,” J. Phys. Chem. Ref. Data 37(2), 913-931 (2008).

${ }^{35}$ R. K. Janev, W. D. Langer, D. E. J. Post, and K. J. Evans, Jr., Elementary Processes in Hydrogen-Helium Plasmas: Cross Sections and Reaction Rate Coefficients (Springer, 1987), Vol. 4, p. 4.

${ }^{36} \mathrm{M}$. D. Shah, "Pulsed crossed-beam study of the ionisation of atomic hydrogen by electron impact," J. Phys. B 20, 3501 (1987).

${ }^{37}$ I. Bray and T. Stelbovicsi, "Calculation of the total ionization cross section and spin asymmetry in electron-hydrogen scattering from threshold to $500 \mathrm{eV}$," Phys. Rev. Lett. 70, 746 (1993).

${ }^{38}$ S. J. Buckman, A. V. Phelps, J. Buckman, and A. V. Phelpsb, "Vibrational excitation of $\mathrm{D} 2$ by low energy electrons vibrational excitation of $\mathrm{O} 2$ by low energy electrons," J. Chem. Phys. 82, 4999 (1985).

${ }^{39} \mathrm{~V}$. G. Anicich, "Evaluated bimolecular ion-molecule gas phase kinetics of positive ions for use in modeling planetary atmospheres, cometary comae, and interstellar clouds,” J. Phys. Chem. Ref. Data 22(6), 1469-1569 (1993).

${ }^{40} \mathrm{C}$. H. Kruger, "Nonequilibrium effects in thermal plasma chemistry," Plasma Chem. Plasma Process. 9(4), 435-443 (1989).

${ }^{41}$ J. Brian, "The dissociative recombination of molecular ions," Phys. Rep. 186(5), 215-248 (1990).

${ }^{42}$ B. J. McCall et al., "Dissociative recombination of rotationally cold $\mathrm{H} 3+$," Phys. Rev. A 70(5), 52716 (2004).

${ }^{43}$ S. Oh, H. Lee, C. Chung, S. Oh, H. Lee, and C. Chung, "Global model including multistep ionizations in helium plasmas," Phys. Plasmas 23(12), 123508 (2016).

${ }^{44}$ W. L. Morgan, http://www.lxcat.laplace.univ-tlse.fr for Morgan database, 2012.

${ }^{45} \mathrm{~A}$. T. Hjartarson, "Low pressure hydrogen discharges diluted with argon explored using a global model," Plasma Sources Sci. Technol. 19, 65088 (2010).

${ }^{46} \mathrm{M}$. Sode, T. Schwarz-Selinger, and W. Jacob, "Ion chemistry in H2-Ar low temperature plasmas,” J. Appl. Phys. 114(6), 063302 (2013).

${ }^{47}$ R. C. Wieggers, P. W. C. Groen, H. J. de Blank, and W. J. Goedheer, "Simulation of the neutral inventory in the Piot-PSI beam," Contrib. Plasma Phys. 52(5-6), 440-444 (2012).

${ }^{48}$ K. Jesko, Y. Marandet, H. Bufferand, J. P. Gunn, and H. J. Van Der Meiden, "Soledge2D-Eirene simulations of the Pilot-PSI linear plasma device compared to experimental data," Contrib. Plasma Phys. 58, 6-8 (2018).

${ }^{49} \mathrm{~B}$. De Groot et al., "Extreme hydrogen plasma fluxes at Pilot-PSI enter the ITER divertor regime," Fusion Eng. Des. 82, 1861-1865 (2007).

${ }^{50} \mathrm{R}$. Wiggers, "B2.5-Eunomia simulations of Pilot-PSI," Ph.D. thesis (Eindhoven University of Technology, 2012).

${ }^{51}$ R. Schneider, X. Bonnin, K. Borrass, D. P. Coster, H. Kastelewicz, and D. Reiter, "Plasma edge physics with B2-Eirene," Contrib. Plasma Phys. 191(1), 3-191 (2006). 
${ }^{52}$ S. I. Braginskii, "Transport processes in a plasma," Rev. Plasma Phys. 1, 205-311 (1965)

${ }^{53}$ Y. Itikawa, "Cross sections for electron collisions with nitrogen molecules," Phys. Chem. Ref. Data 35(1), 31-53 (2006).

${ }^{54} \mathrm{M}$. Koshi et al., "Reactions of $\mathrm{N}\left({ }^{4} \mathrm{~S}\right)$ atoms with $\mathrm{NO}$ and $\mathrm{H}_{2}$," J. Chem. Phys. 93(12), 8703 (1990).

${ }^{55} \mathrm{~T}$. Amano, "The dissociative recombination rate coefficients of $\mathrm{H}_{3}^{+}, \mathrm{HN}_{2}{ }^{+}$, and $\mathrm{HCO}^{+}$, "J. Chem. Phys. 92(11), 6492-6501 (1990).

${ }^{56} \mathrm{D}$. Reiter, The data file AMJUEL: Additional atomic and molecular data for EIRENE FZ, Forschungszentrum Julich GmbH FRG, Version: April 26, 2011 Available via E-mail from d.reiter@fz-juelich.de (2011),pp. 1-393.

${ }^{57}$ S. S. Prasad and W. T. Huntress, "A model for gas phase chemistry in interstellar clouds. I-The basic model, library of chemical reactions, and chemistry among C, N, and O compounds," Astrophys. J. Suppl. Ser. 43, 1 (1980).
${ }^{58}$ G. Park, H. Lee, G. Kim, and J. K. Lee, "Global Model of $\mathrm{He} / \mathrm{O}_{2}$ and $\mathrm{Ar} / \mathrm{O}_{2}$ atmospheric pressure glow discharges," Plasma Processes Polym. 5, 569-576 (2008).

${ }^{59}$ P. L. Bhatnagar, E. P. Gross, and M. Krook, "A model for collision processes in gases. I. Small amplitude processes in charged and neutral one-component systems," Phys. Rev. 94(3), 511-525 (1954).

${ }^{60} \mathrm{~K}$. Jesko, Y. Marandet, H. Bufferand, and J. P. Gunn, "Studying divertor relevant plasmas in the Pilot-PSI linear plasma device: Experiments versus modelling," Plasma Phys. Controlled Fusion 60, 125009 (2018).

${ }^{61} \mathrm{H}$. Bufferand et al., "Implementation of drift velocities and currents in SOLEDGE2D-EIRENE," Nucl. Mater. Energy 12, 852-857 (2017).

${ }^{62} \mathrm{~V}$. Rohde, D. Neuwirth, M. Oberkofler, and U. Team, "Nitrogen balance and ammonia formation during nitrogen seeded discharges at ASDEX Upgrade," in 40th EPS Conference on Plasma Physics, EPS 2013 (2012), pp. 2-5.

${ }^{63} \mathrm{~J}$. H. Van Helden et al., "Detailed study of the plasma-activated catalytic generation of ammonia in N2-H2 plasmas," J. Appl. Phys. 101(4), 043305 (2007). 